Long-term effects of juvenile NMDAr or DAr antagonism on adolescent reward-related neurobehavioral outcomes

\title{
Kate Goheen
}

A thesis submitted to the Faculty of Graduate and Postdoctoral Affairs in partial fulfillment of the requirement for the degree of

Master of Science

in

Neuroscience

\author{
Carleton University \\ Ottawa, Ontario
}

November 2018

CKate Goheen 


\section{Kate Goheen}

Long-term term effects of juvenile treatment of NMDAr or DAr antagonism on adolescent reward-related neurobehavioral outcomes

Previous research from our laboratory found a critical period of development between postnatal day (P)18-P24 in which synaptogenesis occurs with the emergence of spatial performance. Considering the glutamatergic projections from the hippocampus to the nucleus accumbens (NAc), it is likely that they share similar developmental trajectories. Subjects were treated with the dopamine receptor (DAr) antagonist, flupenthixol or the NMDAr antagonist, MK-801 from P18-P24 and were tested in an operant conditioning procedure during adolescence. Another group of subjects were given the same drugs prior to each acquisition session to test immediate effects. Spine densities for the early treatment groups were quantified to measure structural changes in the NAc and c-Fos labeling were quantified after an DA or NMDA agonist to measure receptor desensitization. Early flupenthixol increased locomotor activity during acquisition, which corresponded with an increase in DAr sensitization in the NAc. No behavioural or structural differences were found between the early MK-801 group and saline control. Late flupenthixol decreased operant acquisition and locomotor activity, while late MK-801 increased both. These results demonstrate the importance of increased DA in rewardrelated behaviour, either through the immediate effects of a drug or through DAr sensitization during development. 


\section{Acknowledgements}

I would like to thank my thesis supervisor Dr. Matthew Holahan for your guidance, ingenuity and wit who made the writing of my thesis both possible and enjoyable. I have learned so much in the past two years, thank you for taking on a squeamish Psychology student.

I would like to thank my committee members Dr. Natalina Salmosa and Dr. Hongyu Sun for taking the time to participate in both my prospectus and defense, as well as thoughtfully providing constructive criticism. I would also like to thank Dr. Maria DeRosa for taking time out of her schedule to be the internal-examiner at my defense.

To my lab-mates/friends for moving buildings with me four times and always staying upbeat, thank you for making the past two years a positive adventure. A special thank you to Erin Noye Tuplin who taught me (sometimes twice) lab techniques and gave me critical advice on surviving graduate school.

I would like to thank the subjects, the rats, without whose death would leave many scientific discoveries unturned. You do not go unnoticed.

Lastly I would like to thank my friends and family who supported me throughout the past two years. Thank you for always listening to me and encouraging me. I owe you one. 
Table of contents

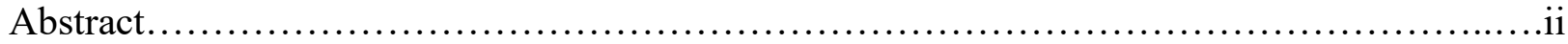

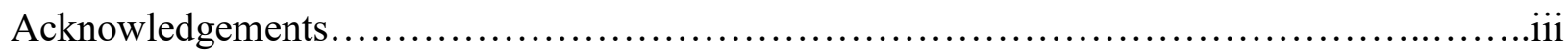

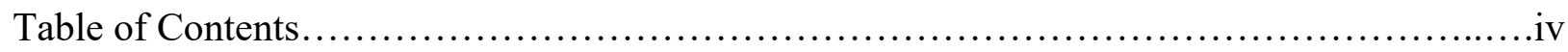

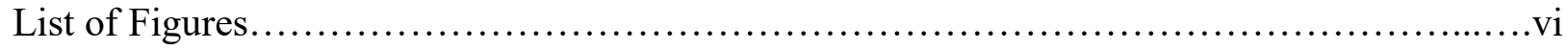

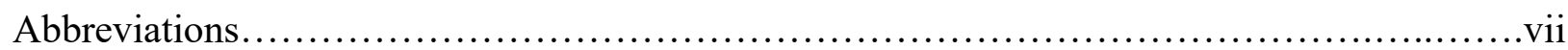

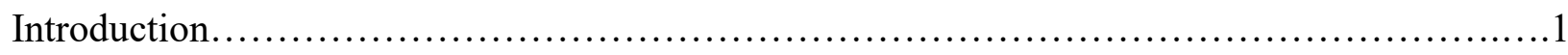

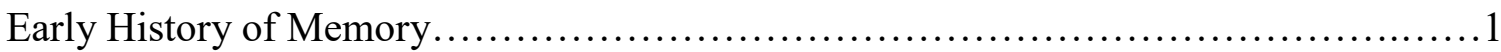

Biological Basis of Memory................................................... 2

The Study of Learning \& Memory..............................................4

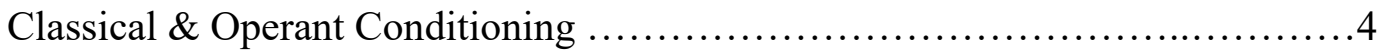

The role of the Nucleus Accumbens in associative learning..........................5

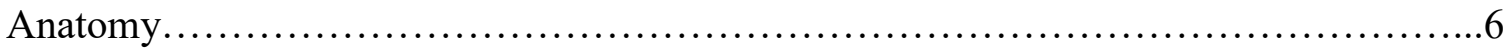

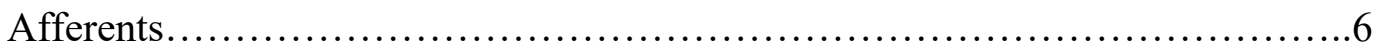

Efferents........................................................6

Neuron Types.....................................................

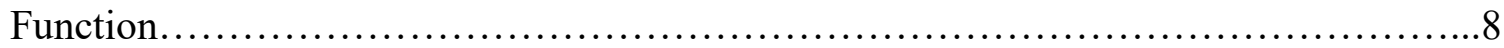

Mechanisms of Learning \& Memory ............................................ 8

LTP in the Mesolimbic Pathway: glutamate \& NMDA.............................. 11

LTP in the Mesolimbic Pathway: dopamine....................................... 13

Development of Associative Learning ............................................ 15

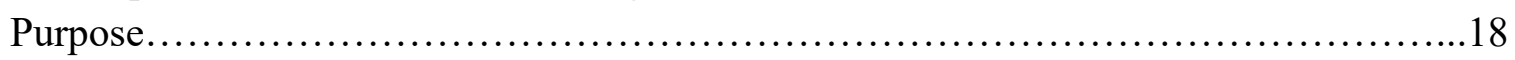

Materials and Methods................................................................ 19

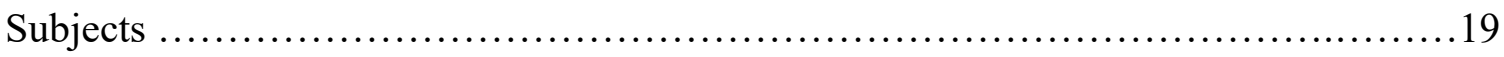

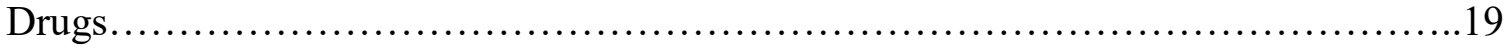

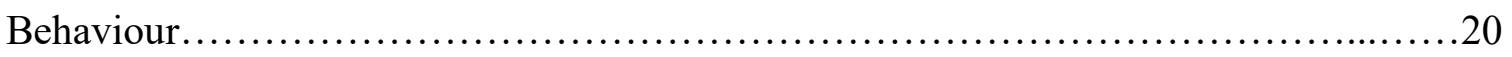

Drug Treatment...................................................... 20

Food Restriction.......................................................... 20

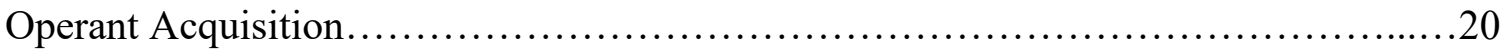

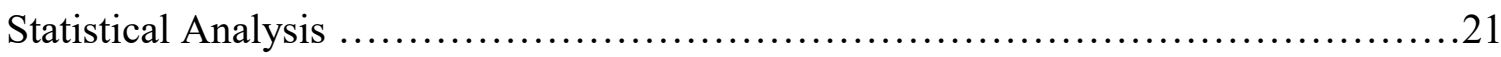

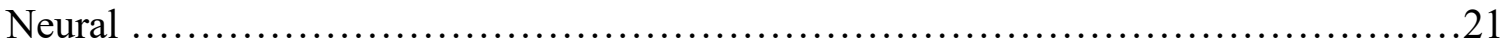

Drug Treatment..................................................... 21

Immunohistochemistry.................................................... 21

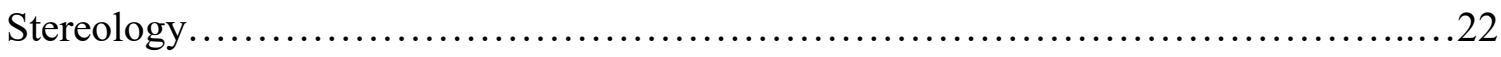

Golgi Cox Staining ........................................................ 23

Morphological Analysis..................................................... 23

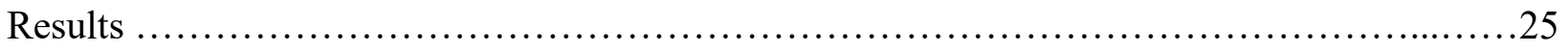


Operant Acquisition........................................................ 25

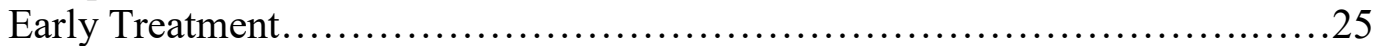

Late Treatment........................................................ 30

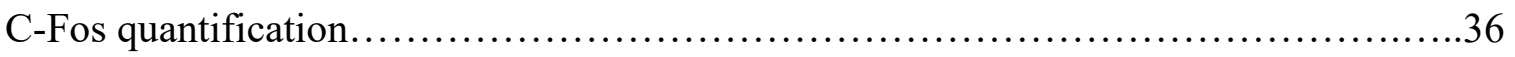

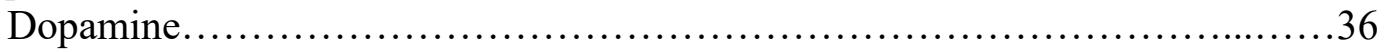

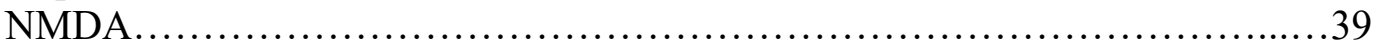

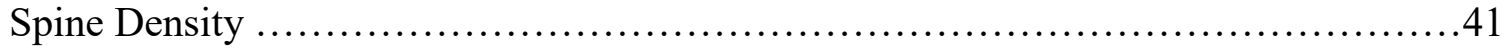

Comparison of Total Activity and c-Fos quantification..........................43

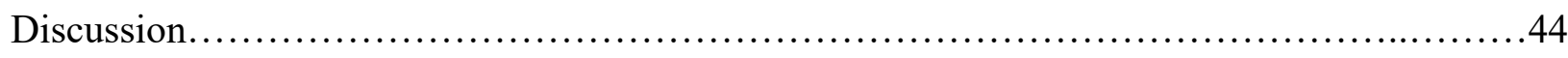

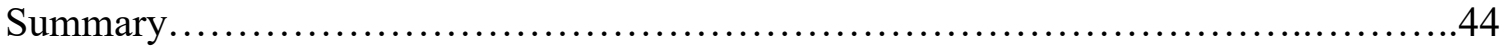

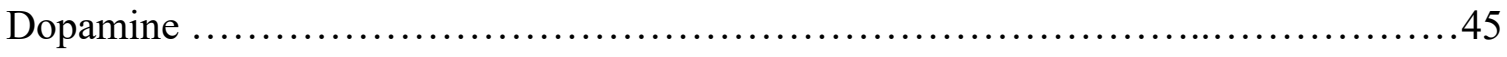

NMDA............................................................. 50

Conclusion \& Future Directions.................................................. 58

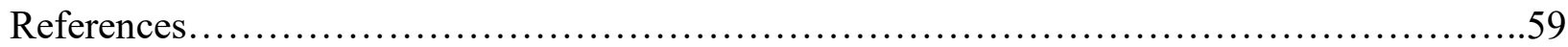




\section{List of Figures}

Figure 1a Daily Active Lever Presses (Early Treatment)

Figure 1b Daily Inactive Lever Presses (Early Treatment)

Figure 1c Daily Port Entries (Early Treatment)

Figure 1d Daily Locomotor Activity (Early Treatment)

Figure 2a Daily Active Lever Presses (Late Treatment)

Figure 2b Daily Inactive Lever Presses (Late Treatment)

Figure 2c Daily Port Entries (Late Treatment)

Figure 2d Daily Locomotor Activity (Late Treatment)

Figure 3 Representative Images of c-Fos labeling (Dopamine)

Figure 4a Mean Cell Density of c-Fos in the NAc core (Dopamine)

Figure 4b Mean Cell Density of c-Fos in the NAc shell (Dopamine)

Figure 5 Representative Images of c-Fos labeling (Dopamine)

Figure 6a Mean Cell Density of c-Fos in the NAc core (Dopamine)

Figure $6 \mathrm{~b}$ Mean Cell Density of c-Fos in the NAc shell (Dopamine)

Figure 7 Representative Images of Dendritic Spines in the NAc

Figure 8a Total Spine Density in the NAc

Figure 8b Total Spine Subtype Densities in the NAc

Figure 9 Total Active Lever Presses and Locomotor Activity Compared with c-Fos results 


\begin{abstract}
Abbreviations
ABC Avidin-Biotin Complex

AP Action Potential

AP-5 (2R)-amino-5-phosphonopentanoate

APV (2R)-amino-5-phosphonovaleric acid

ANOVA Analysis of Variance

AMPA $\alpha$-amino-3-hydroxy-5-methyl-4-isoxazolepropionic acid

$\mathrm{Ca}^{2+}$ Calcium

CaM Calmodulin

CaMKII $\mathrm{Ca}^{2+} /$ calmodulin-dependent protein kinase II

CNQX Cyanquixaline (6-cyano-7-nitroquinoxaline-2,3-dione)

DA Dopamine
\end{abstract}

DAB 3,3'diaminobenzidine

DAr Dopamine receptor

EPSP Excitatory post synaptic potentials

ERK Extracellular signal-regulated kinase

GABA Gamma-aminobutyric acid

LTD Long-term depression

LTP Long-term potentiation

NMDA N-methyl-D-aspartate

NMDAr N-methyl-D-aspartate receptor

$\mathrm{Na}^{+}$Sodium

NAc Nucleus Accumbens 
Mg+ Magnesium

MK-801

MSN Medium Spiny Neurons

PBS Phosphate buffer solution

PFC Prefrontal Cortex

PKA Protein kinase

P Postnatal day

S-R Stimulus-Response

TZG (RS)-(Tetrazol-5-yl) glycine

VTA Ventral Tegmental Area

SN Substantia Nigra 
Introduction

\section{Early History of Memory}

The search for the cellular basis of learning and memory is rooted in an epistemological debate between empiricists and rationalists. At the core are fundamental questions pertaining to the study of knowledge, perception and the material basis of the mind; questions that have been documented since the Ancient Greeks (Aristotle, 384-322 BC; Plato, 427-347 BC). Learning was and continues to be, broadly defined as the modification of future behaviour in response to present environmental conditions. Memory can be defined as the ability of an organism to store and retrieve information. Due to insufficient knowledge about the brain, the better part of the philosophical and scientific endeavor into the material basis of learning and memory was rooted in introspective and logical approaches. In the 17 th and 18th century rationalists, such as Descartes, concluded that the mind was immaterial (Descartes, 1637), whereas most empiricists abstained from commenting on the nature of the mind (Locke, 1693; Hume, 1748). They focused instead on sensory stimuli, learned associations and habit formation, work that would later influence the founder of experimental psychology, William James (Gluck, Mercado \& Myers, 2016). A pursuit originating with good intentions ended with psychologists like Freud and Jung who relied on introspection rather than experimental observation to explain human action and motivation (Gluck, Mercado \& Myers, 2016).

In stark opposition to this approach, Watson formed behaviourism, which became the dominant view during the first half of the 20th century (Petri \& Mishkin, 1994). Being a firm proponent of empiricism, Watson stated that discussion of consciousness and the mind had no place in the field of psychology (Watson, 1913). Advocates for this school of thought stressed that the only scientifically sound method of studying psychology was through behavioural 
observation and viewed learning as a simple stimulus-response association. Cognitive psychologists, from an opposing school of thought, disagreed with such a reductionist view, stating that mental events and expectations contributed significantly to the study of learning (Petri \& Mishkin, 1994). The field became stagnant, with behaviourists and cognitivists arguing between the superiority of behavioural observation versus the necessity to include mental events. Throughout this debate, the cellular basis of learning and memory and the emerging field of neuroscience was largely ignored, despite the fact that both could help settle the debate.

\section{Biological Basis of Memory}

Significant progress in the field of neuroscience occurred when, in 1873, Camillo Golgi developed a method for staining cells that captured axonal and dendritic visibility (Climino, 1999). This led him to support the reticular theory, originally proposed by Joseph von Gerlach, and erroneously conclude that cells in the nervous system are continuous; an idea he continued to espouse despite increasing evidence in favour of nerve cell discontinuity (Cajal 1888, Golgi, 1906; Climino, 1999; Sotelo, 2003). The now established neuron doctrine was originally suggested by Ramon y Cajal when he demonstrated that nerve cells were separate from each other but interconnected by synapses (Cajal, 1906). In addition, he was among the first to propose a theory about the cellular basis of learning (Miles et al., 2005) postulating that as

learning occurred, pre-existing connections between neurons strengthened, thereby increasing synaptic efficiency.

Donald Hebb later expanded on the position of Cajal in his book The Organization of Behaviour (Hebb, 1949). The goal was to settle the debate between behaviourists and cognitivists by developing a coherent theory of the mind that redefined it as a physiological entity. In an effort to bridge the gap between psychologists, physiologists, and chemists, he 
believed that it was necessary to merge physiological data from the nervous system with behavioural data from experimental observation. Examining how they influenced one another rather than studying them independently would result in a more complete understanding of human nature. By redefining the concept of the mind as neural activity, he provided a framework in which researchers from different fields and schools of thought could have dialogue and collaborate. Hebb's framework gave behaviourists the opportunity to move away from a simple stimulus-response explanation of behaviour while keeping their empirical rigor. It permitted cognitivists to discuss mental processes without sounding "mystical" (Hebb, 1949) and allowed the narrow focus of physiologists to be broadened by integrating their data with those collected by psychologists.

An important contribution that Hebb made to the beginnings of the physiological psychology movement centered on how behavior could change the brain. Hebb proposed that after repeated stimulation, different "cell-assemblies", namely a particular set of neurons, would develop and fire together, often resulting in a permanent change in behaviour. Cell assemblies only develop when the cells are mutually active and a cell-assembly could occur in response to external stimuli, activity in a previous cell-assembly or from both. Thoughts were also proposed to arise from a series of cell assemblies, which Hebb termed a "phase sequence". Hebb proposed that cell assemblies could disassemble when repeated stimulation from a particular stimulus was no longer present. Therefore, from Hebb's perspective, learning and memory were thought to occur through the creation and strengthening of synapses, while forgetting occurred through the weakening of synapse. Hebbian plasticity was theoretically in place, but empirical support was needed. 


\section{The Study of Learning and Memory}

\section{Classical \& Operant Conditioning}

Though radical behaviourism disappeared, many of the procedures put forth by the school of thought are still widely used today. While Watson was viewed as the founder of behaviourism, the beginning of the experimental study of learning can be accredited to the physiologist Ivan Pavlov (Pavlov, 1927). Interested in the physiology of salivation and digestion, Pavlov began to systematically study the salivation of dogs in response to food. He soon discovered that he could elicit a salivary response by a stimulus that predicted the delivery of food. This response became stronger after repeated pairings of a bell with the food and could be elicited by the bell alone. This type of learning in which a previously neutral stimulus (bell) elicits a conditioned response (salivation) after repeated pairings with an unconditioned stimulus (food) is known as classical conditioning. Pavlov also demonstrated a process called extinction, in which a conditioned response is weakened when the conditioned stimulus (bell) is no longer paired with, and thus no longer predicts, the unconditioned stimulus.

During this time, another form of associative learning was discovered in the laboratory of Edward Thorndike (Thorndike, 1911). Instrumental or operant conditioning occurs when a frequency of a behaviour is either increased or decreased following the presence or absence of an outcome. Thorndike observed that cats who were locked in a box were able to be trained to solve a type of puzzle that unlocked the box, specifically their frequency of "unlocking" behaviour increased in order to obtain a favourable outcome. Instrumental, unlike classical conditioning, requires an organism to make a response in order to obtain a specific outcome. Associative learning occurs in all mammals, including humans, making classical and operant conditioning 
procedures robust measures of learning that allow experimenters to infer underlying mechanisms across species.

The foundation of behaviourism was largely influenced by the principles of associative learning discovered by Pavlov and Thorndike. The widely used Skinner box, named after the inventor, was developed in 1930 (Gluck, Mercado \& Myers, 2016). The original apparatus was a box with a lever that, when pressed, delivered food. An animal placed in the box would explore and eventually press the lever and receive food. Once animals learned the relationship between pressing the lever (response) and the delivery of food (outcome), their rate of response would increase. Since the inception of the Skinner box, there have been many experimental manipulations of the apparatus, allowing researchers to explore the intricacies of operant conditioning and associative learning. For example, standard operant chambers use two levers to assess stimulus discrimination, where pressing one lever results in food delivery, and pressing the other lever does not (Tuplin, Stocco, Holahan, 2015).

During associative learning, two parallel processes occur: both the response-outcome relationship and the value of the reward is learned. When analyzing behavioural data, it is often difficult to distinguish between learning and motivational processes. These two components are likely mediated by different neurochemical pathways, and understanding the subtle nuance between the two may require different behavioural and neurochemical manipulations.

\section{The role of the Nucleus Accumbens in associative learning}

On a neural level, associative learning occurs through the strengthening of connections between motor neurons (response) and either sensory (stimulus) or cortical neurons (reward expectancy) (Donahoe \& Palmer, 1994; Donahoe, Palmer \& Burgos, 1997). One pathway involved is the mesocorticolimbic dopamine system, where dopaminergic projections are 
activated from the substantia nigra (SN) and ventral tegmental area (VTA) to the dorsal and ventral striatum (Gerfen, Herkenham, \& Thibault, 1987).

\section{Anatomy}

\section{Afferents}

The nucleus accumbens (NAc) is located in the ventral striatum and can be anatomically divided into a central core, which is surrounded medially, ventrally and laterally by the shell (Zaborsky et al., 1985; Zahm \& Brog, 1992). The NAc receives direct dopaminergic input from the VTA and SN, predominantly to the shell and core respectively (Gipson, Kupchick \& Kalivas, 2014; Moore \& Bloom, 1978; Gerfen, Herkenham \& Thibault, 1987; Nirenberg et al., 1996). A subset of the dopaminergic neurons from the VTA express the vesicular transporter VGLUT2 and corelease glutamate in the NAc (Kawano et al., 2006; Yamaguchi et al., 2011). Additionally, independent glutamatergic neurons project to the NAc (Yamaguchi, Sheen \& Morales, 2007; Nair-Roberts et al., 2008) and synapse with DA neurons locally (Dobi et al., 2010). The NAc receives direct glutamatergic input from the basolateral amygdala, ventral hippocampus, thalamus, VTA, prelimbic and prefrontal cortex (Gipson, Kupchick \& Kalivas, 2014; Powell \& Leman, 1976; Kelley et al., 1982). The core predominantly receives input from the dorsal prelimbic, anterior insular, anterior cingulate and perirhinal cortices while the shell receives input from the dorsal peduncular, infralimbic and piriform cortices (Brog et al., 1993; Salgado \& Kaplitt, 2014).

\section{Efferents}

Inhibitory gamma-aminobutyric acid (GABA) pathways project from the NAc to areas in the basal ganglia and midbrain including the ventral pallidum, thalamus and lateral hypothalamus (William, Crossman \& Slater, 1977; Churchill \& Kalivas, 1994; Floresco, 2015; 
Salgado \& Kaplitt, 2014). The shell projects to the extended amygdala, VTA and ventromedial ventral pallidum (Heimer et al., 1991; van Kuyck et al., 2007), while the core projects to the dorsolateral ventral pallidum, lateral VTA and dorsal pas compacta (Zahm \& Heimer, 1993).

\section{Neuron Types}

The NAc is primarily made up of GABAergic medium spiny neurons (MSNs) expressing D1 and D2 dopamine receptors (Kawaguchi et al., 1995; Yager et al., 2015), the remaining estimated 5\% are GABAergic and cholinergic interneurons (Meredith, 1999). MSNs expressing D1 receptors project directly to the $\mathrm{SN}$, whereas MSNs expressing D2 receptors project indirectly to the SN through the globus pallidus (Gerfen, 1992). Though few in comparison, the interneurons are critically involved in the function of the NAc (Kreitzer, 2009). The core is denser than the shell, with larger cell bodies, and a higher density of dendrites and dendritic spines (Meredith, Blank \& Groenewegen, 1989; Meredith et al., 1992). The core has more GABAA receptors (Churchill et al., 1992), while the shell has more serotonin receptors (Patel, 1995).

\section{Function}

The NAc is a part of the mesocorticolimbic dopamine system, which as a whole, composes the reward system. The NAc itself acts as an interface between motor and limbic systems due to its efferent projections to the former and afferent projections from the latter (Mogenson, Jones \& Yim, 1980), making it a prime candidate for initiating behaviour in response to sensory stimuli (Shiflett \& Balleine, 2011). It is involved in reward-associative learning, habit formation and compulsive behaviour.

Lesions to the NAc impair instrumental lever pressing for both food and sucrose (Balleine \& Kilcross, 1994; Borchgrave et al., 2002). Lesioned rats were not sensitive to changes 
in the value of the reward produced by increased food deprivation or sucrose concentration. A functional dissociation between the NAc core and shell was found (Corbit, Muir, \& Balleine, 2001), with NAc core lesioned rats pressing significantly less during acquisition than NAc shell or sham controls. NAc core lesioned rats were not affected by outcome devaluation, in that they pressed equally for two rewards that had different values. Lesions to the NAc do not appear to affect extinction (Wang et al., 2008; Stern \& Passingham, 1996), though the NAc core is involved in reactivation of reward-seeking behaviour after extinction (Wang et al., 2008).

\section{Mechanisms of Learning and Memory}

Lomo \& Bliss (1973) are credited with the discovery of long-term potentiation (LTP) and depression (LTD) on the hippocampal synapse between the perforant path and dentate area. Their seminal work laid the necessary groundwork providing the opportunity for subsequent researchers to provide empirical evidence in support of Hebbian plasticity. They demonstrated, first in vitro (Lomo, 1966) and then in vivo that high-frequency presynaptic stimulation gives rise to long-lasting excitatory postsynaptic potentials (EPSP). The recorded LTP at the postsynaptic cell outlasted the stimulation from minutes to hours and was the first demonstration that an event as transient as an action potential could create long-lasting changes. Lomo \& Bliss posited that LTP could be involved in memory storage, partly because it was demonstrated in the hippocampus, a region viewed as being associated with learning and memory (Lomo \& Bliss, 1973; Douglas, 1967). However, they could only hypothesize as to what was occurring and whether this could occur naturally in an organism. They suggested, among other propositions, that this increase in synaptic efficiency could be due to an increase in neurotransmitter release presynaptically or an increase in post-synaptic sensitivity. 
Collingridge et al. (1983) sought to examine these hypotheses by experimenting with the CA3-CA1 synapse in the hippocampus. At the time, it was known that this synapse was excitatory, but it was unclear whether the neurotransmitter released was glutamate or 1-asparate. Furthermore, the receptor subtypes were just beginning to be categorized and potent antagonists were being created (Davies et al., 1981). With the development of an NMDA receptor (NMDAr) antagonist, Collingridge was able to demonstrate that NMDAr were unnecessary for normal transmission, but that blocking NMDAr prevented LTP induction despite normal depolarization of the post synaptic target. Concurrently, it was demonstrated that intracellular injections of a calcium blocker in CA1 neurons blocked LTP induction indicating that LTP was dependent on calcium influx (Lynch et al., 1983; Miles et al., 2005). Both results supported the notion that LTP expression occurred at the post and not the presynaptic membrane. Kullman (1994) was able to confirm this hypothesis by recording receptor specific synaptic signals at baseline compared to after LTP induction. Through this, he discovered that AMPA receptor signals change but NMDAr do not, indicating that the former is latent at baseline and increase after LTP. These findings lead him to propose that a rise in AMPA receptors was behind the expression of increased synaptic efficiency. Therefore, the same amount of presynaptic neurotransmitter release would have more receptors to bind to, causing a larger depolarization.

It is now known that LTP and LTD occur at excitatory glutamatergic synapses, where the ionotropic AMPA receptor (AMPAr) allows the influx of sodium $(\mathrm{Na}+)$ ions, but the voltagedependent NMDA receptor channel is blocked by magnesium (Mg+) (Dingledine et al., 1999). With enough presynaptic glutamatergic stimulation, Na+ floods in through AMPAR channels and pushes out the magnesium $(\mathrm{Mg}+)$ block through electrostatic repulsion allowing $\mathrm{Na}+$ and calcium $(\mathrm{Ca} 2+)$ influx via NMDAR. The level of postsynaptic $\mathrm{Ca} 2+$ determines whether LTP or 
LTD occur (Lisman, 1989). In LTP, Ca2+ binds to calmodulin (CaM) and activates the Ca2+/calmodulin-dependent protein kinase II (CaMKII) (Malenka et al., 1988) which can facilitate the insertion of AMPAr into the post-synaptic neuron (Zamanillo et al., 1999). In LTD, less $\mathrm{Ca} 2+$ enters the postsynaptic cell, causing an activation of protein phosphatases, eventually leading to AMPAr internalization (Beattie et al., 2000).

Hebb, in his theory of plasticity, proposed 1) an increase in synaptic efficiency when neurons fire mutually and 2) the creation of connections between neurons, presently referred to as synaptogenesis. The first part of the theory was verified through the finding that synaptic strengthening or weakening was expressed through levels of AMPAr postsynaptically as well as the finding that NMDAr act as coincident detectors, requiring both pre and postsynaptic stimulation for LTP induction (Zorumski \& Izumi, 2012). The second part of the theory requires a process expanding further than the synapse.

Much of what is known of LTP and LTD is from work on the hippocampus. However, LTP and LTD are more than the cellular basis of learning and memory, rather they can be thought of as a form of synaptic plasticity. Neural plasticity occurs in other regions besides the hippocampus, such as the mesolimbic pathway (Bonci \& Malenka, 1999; Robbe, Bockaert \& Manzoni, 2002) and many genes related to plasticity including those that encode protein kinases and cAMP response element-binding protein (CREB) are found in the striatum and cortex (Kelley, 2004). The study of neural plasticity covers a much broader range of topics including development, post-injury, addiction, epilepsy, and pain.

\section{LTP in Mesolimbic pathways: Glutamate and NMDA}

The role of dopamine in reward-based learning has been the primary focus of research but the role of glutamate is of equal importance. As stated previously, the NAc receives 
excitatory glutamatergic input from the prelimbic and prefrontal cortex, as well as the basolateral amygdala, hippocampus, and VTA. The induction of LTP and LTD has been demonstrated in the VTA (Bonci \& Malenka, 1999; Bellone \& Lusher, 2005), amygdala (Nabavi et al., 2014) and NAc (Robbe, Bockaert \& Manzoni, 2002; Meredith, Pennartz \& Groenewegen 1993). Most research on synaptic plasticity in the striatum has focused on corticostriatal synapses, rather than limbic-striatal synapses (Cerovic et al., 2013).

Calabresi et al. (1992) conducted one of the first studies demonstrating synaptic plasticity at corticostriatal synapses. EPSPs were induced by tetanic stimulation of cortical inputs, and this was blocked using the AMPAr antagonist cyanquixaline (6-cyano-7-nitroquinoxaline-2,3-dione) (CNQX), but not by the NMDAr antagonist (2R)-amino-5-phosphonovaleric acid (APV). When slices were bathed in a Mg2+ control condition, tetanic cortical stimulation produced LTD, demonstrating that tetanic stimulation in regular conditions produces LTD rather than LTP. In a $\mathrm{Mg} 2+$ free medium, cortical stimulation produced LTP, which was then blocked by an AMPAr antagonist, but not an NMDAr antagonist, demonstrating an NMDAr independent form of LTP. It is now understood that striatal LTP varies and can be influenced by numerous factors including region, the age of development, and whether the experiment is in vivo or in vitro (Filippo et al., 2009). LTP in the NAc has been evoked using high-frequency stimulation, but this method is not ecologically valid because high frequency $(100 \mathrm{~Hz})$ LTP is found in less than $20 \%$ of MSNs (Kombian \& Malenka, 1994; Schramm, Egli \& Winder., 2002) and most MSNs fire between 1 and $10 \mathrm{~Hz}$ (Carelli \& Ijames, 2000). Glutamatergic neurons in the prefrontal cortex (PFC) and amygdala that project to the NAc also fire at a similar rate (Margrie, Brecht \& Sakmann, 2002; Puig et al, 2003) Therefore, using a spike-timing-dependent plasticity model, a method that pairs action potential with EPSPs at a lower frequency may be more physiologically 
relevant than high-frequency stimulation when studying synaptic plasticity in the NAc (Ji \& Martin, 2012).

Ji \& Martin (2012) investigated synaptic plasticity in MSNs in the NAc core using varying conditions by combining different action potential (AP) frequencies $(0.2,1$ and $5 \mathrm{~Hz})$ with varying delays between AP and ESPS pairings (10, 20, 50 and 200ms). Two subgroups of MSNs emerged across experimental conditions, in which either LTP or LTD was induced. LTPMSNs were influenced by the frequency and delay of AP-EPSPs, whereas LTD-MSNs were not. An NMDA antagonist blocked LTP-MSNs, whereas antagonizing calcium channels blocked LTD-MSNs. These data underscore the challenging nature of studying synaptic plasticity in the NAc.

The behavioural effect of NMDAr blockade was demonstrated using an operant task (Kelley, Smith-Roe, \& Holahan, 1997). Rats were trained to lever press for a food reward and received infusions of an NMDAR antagonist (2R)-amino-5-phosphonopentanoate (AP-5) before or after training. NMDAR dependent plasticity in the NAc core, basolateral amygdala, and medial PFC was found to be necessary for the acquisition of the task. Infusions of AP-5 in the NAc shell impaired learning to a lesser degree. Once the task was learned, AP-5 had no effect indicating that NMDA is necessary during the early stages of learning but not the expression phase. The necessity of synaptic plasticity for instrumental learning was further demonstrated by inhibiting protein synthesis following acquisition trials. Synaptic plasticity in the NAc core, but not the shell, was necessary for memory consolidation during acquisition. Once the task was learned, protein synthesis inhibition had no effect (Hernandez, Sadeghian \& Kelley, 2002). 


\section{LTP in the Mesolimbic Pathway: dopamine}

MSNs in the striatum contain both dopaminergic and glutamatergic receptors located in close proximity to each other (Smith \& Bolam, 1990; Sesack et al., 2003; Shiflett \& Balleine, 2011). The NAc receives dopaminergic input from the VTA and SN, both synapsing on striatal MSNs which express either D1 or D2 dopaminergic receptors (Smith \& Bolam, 1990; Shiflett \& Balleine, 2011). Excitatory glutamatergic afferents are thought to interact with DA neurons from VTA to NAc, increasing repetition of behaviours under certain environmental conditions (Chen, Hopf \& Bonci, 2010).

DA released from midbrain neurons act as a signal to predict reward, by firing when there is a discrepancy between reward expectation and behavioural outcome (Schultz, 1999). For example, in Pavlovian conditioning, the VTA fires and DA is released to unexpected rewards. However, once the delivery of a reward is predicted, VTA neurons no longer fire. Instead, they fire to the presentation of the conditioned stimulus, that is, they fire to the prediction of a reward. During extinction, DA firing is decreased when the reward is no longer presented, signaling that the conditioned stimulus no longer predicts the reward.

In a study using intracranial self-stimulation of the $\mathrm{SN}$, rats lever pressed for electrical stimulation, which released DA onto MSNs (Reynolds, Hyland \& Wickens, 2001). After the task was learned, the rate at which each rat pressed the lever was calculated. Electrical stimulation was applied to the $\mathrm{SN}$ at the individualized rate for each rat producing synaptic potentiation at corticostriatal synapses. The degree of potentiation induced by the optimal electrical stimulation was correlated to the rate at which each rat learned, suggesting that DA helps strengthen corticostriatal synapses and is associated with the rate of instrumental learning. Potentiation was 
blocked using a D1 receptor antagonist, suggesting that DA contributes to corticostriatal synaptic plasticity through these receptors.

LTP has frequently been observed in MSNs expressing D1 receptors, (Calabresi et al., 2000; Kerr \& Wickens, 2001). However, in the absence of D1 receptor binding, LTD occurs when these corticostriatal synapses are activated (Shen et al., 2008). This suggests that DA acts as a signal, strengthening the synapses when the cortical environmental input and striatal behavioural output is rewarding. Importantly, phasic DA firing and not single-bursts of DA is necessary for LTP induction. This is because D1 receptors have low affinity to DA and require high concentrations for binding (Creese et al., 1983; Gonan, 1997). In the absence or low levels of DA, LTD occurs, reducing the likelihood that the same cortical input will result in striatal output. For example, if a rat is given the choice of two levers and is expecting the delivery of a food pellet, pressing the correct lever will result in DA firing and a strengthening between the cortical reward expectancy and the striatal action (Shiflett \& Balleine, 2011; Horvitz, 2009). Pressing the incorrect lever will result in LTD in that active corticostriatal synapse, decreasing the likelihood of future incorrect lever presses.

Intracellular molecules that act as coincidence detectors to DA and glutamate are critically involved in synaptic plasticity and instrumental behaviour (Shiflett \& Balleine, 2011; Nakano et al., 2010). For example, extracellular signal-regulated kinase (ERK) reaches maximum activity following the combined activity of D1 and glutamate receptor activation (Girault et al., 2007). Many proteins involved in synaptic plasticity, such as protein kinase, CREB, and c-Fos are regulated by DAr and NMDAr (Kelley, 2004). D1 and D2 receptors act in opposing ways on intracellular pathways, partly by increasing or decreasing adenylyl cyclase, respectively (Greengard, 2001; Surmeier et al., 2007). An increase in adenylyl cyclase increases 
cAMP and cAMP-dependent protein kinase (PKA). PKA strengthens synaptic plasticity by phosphorylating ion channels, receptors, and transcription factors, downstream effects result in an increase in postsynaptic AMPAr insertion (Surmeier et al., 2007). D2 receptor activation decreases adenylyl cyclase and reduces cellular excitability (Surmeier et al., 2007). The subtypes of MSNs demonstrated by Ji \& Martin (2012) were likely D1 and D2 expressing MSNs.

\section{Development of Associative Learning}

Processes that govern synaptic plasticity, such as LTP and LTD, also govern the development of neural circuits (Durand, Kovalchuk \& Konnert, 1996; Ben-Ari et al., 1997). During the first week of postnatal development in the hippocampus, glutamatergic synapses gradually become functional (Durand, Kovalchuk \& Konnert, 1996). During P1 and P2 only NMDA receptors exist and by P6, they are colocalized with AMPAr. A pairing protocol was used in slices of P1 hippocampal neurons in which presynaptic stimulation was paired with postsynaptic depotentiation. The natural development of glutamatergic synapse was reproduced and the purely NMDA synapses became functional. This "synaptic induction" was blocked by the AMPA antagonist CNQX, indicating that the development and function of glutamatergic receptors was due to the presence of AMPAr (Goodman \& Shatz, 1993; Choi \& Lovinger, 1997).

The processes involved in synaptic plasticity and development occur in tandem, often influencing one another. The theory that the environment can influence the trajectory of neural development and that these changes can influence subsequent plasticity is referred to as metaplasticity, or the plasticity of plasticity (Kania et al., 2017). First coined by Abraham \& Bear (1996), metaplasticity refers to the idea that when studying plasticity, it is not only important to consider what is happening at present during LTP and LTD, but to acknowledge the history of 
the neuron and synapse as well, which may influence the capacity of plasticity at that particular synapse.

Developmental metaplasticity has been mainly studied in the visual cortex, but information gained from these studies is likely relevant to regions involved in associative learning. For example, Kirkwood, Rioult \& Bear, (1996) demonstrated that during a critical period of visual development, the threshold at which presynaptic glutamatergic stimulation triggers either LTP or LTD can change based on the environment, in this case, light deprivation. Importantly, this effect can be reversed after light exposure during the critical period. This threshold modification is likely due to changes in NMDAr subunits during development. NMDAr consist of four subunits: two NR1 and two that can be NR2 (A, B, C or D) or NR3 (A or B) (Cull-Candy \& Leszkiewics, 2001). The combination of subunits determine the function (Cull-Candy \& Leszkiewics, 2004). The ratio of NR2A to NR2B changes during development, and it is hypothesized that this may affect LTP and LTD by changing the permeability of NMDAr to Ca2+ (Yashiro \& Philpot, 2008). However light deprivation may disrupt the normal developmental ratio of NR2A/NR2B, thereby disrupting the threshold at which LTP and LTD occur. It is reasonable to believe that similar processes may be disrupted by exposure to environmental factors during different critical periods during the development of other neural regions.

Unlike sensory and motor neural regions, regions underlying associative learning have a longer developmental trajectory. Previous research has determined a sensitive period in hippocampal development between P18-P24 in which synaptogenesis correlates with the emergence of spatial performance (Tzakis et al., 2016). Considering the glutamatergic 
projections from the hippocampus to the NAc and PFC, they likely share a similar developmental period. (Zaczek, Hedreen \& Coyle 1979; Jay \& Witter 1991).

The mesolimbic dopamine system of the rat continues to develop throughout the first four postnatal weeks (Voorn et al., 1988; Tepper, Trent \& Nakamura, 1990; Wang \& Pitts, 1994). In the nucleus accumbens, DA neurons continue to distribute and grow past PN week three (Voorn et al., 1988). Nigrostriatal dopamine neurons do not reach maximum velocity until PN week three and adult firing patterns until PN week four (Tepper, Trent \& Nakamura, 1990). In the prefrontal cortex, the density of DA neurons continues to increase until P60 (Kalsbeek et al., 1988). The properties of striatal neurons change throughout development (Choi \& Lovinger, 1997). When comparing striatal slices from P10-P19 with P23-P27, the likelihood of neurotransmitter release as well as the magnitude of LTD induction decreased with age.

Rodent adolescence occurs from approximately P28-P42 (Spear, 2000), but may extend to P55 which would coincide with late adolescents and emerging adulthood seen in humans (Vetter-O'Hagen \& Spear, 2012). Adolescent humans and laboratory animals are particularly sensitive to rewarding stimuli (Doremus-Fitzwater et al., 2010; van Duijvenvoorde et al., 2016), are more sensitive to palatable foods (Friemel, Spanagel, \& Schneider, 2010) and exhibit increased goal-directed behaviour (see review Doremus-Fitzwater \& Spear, 2016) .

\section{Purpose}

The purpose of this thesis was to determine the contribution of NMDAr and DAr in the development of associative learning circuitry by using an instrumental conditioning assay. This was done by using chronic treatment with either the NMDAr antagonist MK-801 or the DAr antagonist flupenthixol during a critical period of development (P18-24) followed by instrumental conditioning in adolescence. Two hypotheses were explored to help explain what 
form of developmental plasticity contributed to the behavioural outcomes. The structural plasticity hypothesis posited that early treatment with either an NMDAr antagonist or DAr antagonist would disrupt the structural integrity of the NAc, manifesting as reduced spine density. The synaptic plasticity hypothesis posited that preadolescent DAr or NMDAr antagonism would desensitize receptors in adolescence. Receptor desensitization would manifest by reduced c-Fos labelling following an acute injection of the DA agonist apomorphine or the NMDA agonist TZG. These neural measures would help explore plasticity both structurally and at the level of the synapse. Looking at both dendritic spine density as well as receptor function allows us to gain insight into how the neurons in the NAc might be responding during operant conditioning. 


\section{Materials and Methods}

\section{Subjects}

Pregnant Long-Evans $(\mathrm{n}=15)$ female rats were obtained from Charles River, Quebec and were single-housed in clear plastic cages $(25 \times 20 \times 45 \mathrm{~cm})$. They were given ad libitum access to food and water and were housed in a temperature controlled environment with a 12-hour light/dark cycle (lights on at $8 \mathrm{am}$ ). The day the pups were born was recorded as postnatal day (P) 0. Female pups were culled at P12 and the males were weaned at P18. Pups were housed in groups of 3 or 4 , were given a red plastic tube for enrichment and had ad libitum access to food and water. Pups were either used for behaviour $(n=48)$ or neural analysis $(n=30)$. Procedures were approved by the Carleton University Animal Care Committee and were in agreement with the Canadian Council on Animal Care.

\section{Drugs}

The noncompetitive NMDAr antagonist (+)-5-methyl-10, 11-dihydro-5H-dibenzo [a, d,] cyclohepten-5-10-imine maleate (MK-801) (Sigma-Aldrich) was dissolved in 0.9\% sterile saline to the concentration of $0.05 \mathrm{mg} / \mathrm{kg}$ with $\mathrm{dH}_{2} \mathrm{O}$ and stored frozen. $\mathrm{MK}-801$ at doses of $0.05 \mathrm{mg} / \mathrm{kg}$, $0.1 \mathrm{mg} / \mathrm{kg}$ and $0.2 \mathrm{mg} / \mathrm{kg}$ reached maximal concentration an hour post injection (IP) (Wegener et al., 2011). The $0.05 \mathrm{mg} / \mathrm{kg}$ reached a maximal concentration of $6.02 \mathrm{nM}$, while doses of $0.1 \mathrm{mg} / \mathrm{kg}$ and $0.2 \mathrm{mg} / \mathrm{kg}$ reached concentrations of $14.34 \mathrm{nM}$ and $34 \mathrm{nM}$, respectively. Because MK-801 has been demonstrated to occupy receptors at a concentration of 3nM (Reynolds, Murphy \& Miller, 1987)., the dose chosen for the present work would be sufficient to produce NMDAr blockade. The nonselective DA antagonist Flupenthixol (Sigma-Aldrich) was diluted to a concentration of $0.25 \mathrm{mg} / \mathrm{kg} .0 .9 \%$ sterile saline was used as a control injection. The NMDA agonist (RS)(Tetrazol-5-yl) glycine (TZG) (Sigma-Aldrich) is a highly selective and potent NMDA agonist 
that readily crosses the blood brain barrier (Schoepp et al., 1991). TZG was diluted to a subseizure concentration of $0.1247 \mathrm{mg} / \mathrm{kg}$. The nonselective DA agonist Apomorphine (SignmaAldrich) was diluted to the concentration of $3 \mathrm{mg} / \mathrm{kg}$.

\section{Behaviour}

\section{Drug Treatment}

From P18-P24 half of the pups ( $\mathrm{n}=24)$ used for behaviour were injected subcutaneously each day with either saline, MK- 801 or Flupenthixol at a volume of $0.1 \mathrm{ml}$. Rats that did not receive an early treatment with a drug were randomly assigned to receive subcutaneous injections of MK-801, flupenthixol or saline 15 minutes prior to the beginning of each trial at a volume of $0.1 \mathrm{ml}$.

\section{Food Restriction}

One week prior to, and during operant conditioning (around P30) pups ( $\mathrm{n}=48)$ were single housed and food restricted to approximately $90 \%$ of their weight using an aged matched control.

\section{Operant Acquisition}

Six conditioning chambers (Coulborn Instruments, Whitehall, PA; $30.5 \mathrm{~cm}$ x $25.5 \mathrm{com}$ x $30.5 \mathrm{~cm}$ ) were used to conduct the operant conditioning procedures. Chambers were made of Plexiglas and stainless steel and were located in ventilated, sound attenuating boxes. Two levers were located on the right wall with a port in between. A house light signaled the beginning of each session. During acquisition, rats were placed into the chambers for 30 minutes for a total of five days. Every uninterrupted second response (FR2 schedule) on the left lever (active lever) resulted in the delivery of a $45 \mathrm{mg}$ chocolate pellet (BioServe, New Jersey). This was paired with 
the cue light located above the left lever switching from red to green and the house lights extinguishing. Presses on the right lever (inactive) were not rewarded.

\section{Statistical analysis}

The acquisition (and extinction) data were analyzed using a two-way, repeated measures analysis of variance (ANOVA) with treatment group as the between factor. For the acquisition data total active lever presses, inactive lever presses, port entries or locomotor activity over the 5 days were used as the repeated measure. For extinction, data after each five-minute interval was used as the repeated measure. Post-hoc comparisons were performed if ANOVAs were significant.

Neural Analysis

\section{Drug Treatment}

The second group of pups $(\mathrm{n}=30)$ were treated with MK-801, flupenthixol or saline at a volume of $0.1 \mathrm{ml}$ daily from P18-P24. From P33-P41, they were single caged and food restricted to $90 \%$ of their weight. A P41 they were given an injection of TZG, apomorphine or saline. Rats pretreated with MK-801 received an injection of TZG or saline (IP, $0.3 \mathrm{ml}$ ). Rats pretreated with flupenthixol received an injection of apomorphine or saline (IP, $0.3 \mathrm{ml})$. Rats pretreated with saline received an injection of saline, TZG or apomorphine. 90 minutes later, rats were perfused and their brains were removed.

\section{Immunohistochemistry}

One hemisphere from each subject was fixed in $4 \%$ paraformaldehyde in $0.01 \mathrm{M}$ phosphate buffer solution (PBS, $\mathrm{pH}$ 7.4). The following day they were placed in a $30 \%$ sucrose in $0.1 \mathrm{M}$ PBS and stored at $4^{\circ} \mathrm{C}$. Brains were sectioned on a Leica CM1900 cryostat (Weztler, 
Germany) at 35 um and placed in well plates filled with a $0.1 \%$ sodium azide solution in $0.1 \mathrm{M}$ PBS.

Sections were washed three times for 7 minutes in $0.01 \mathrm{M}$ PBS solution with $0.2 \%$ Triton $\mathrm{X}$ (PBS-TX). They were incubated in hydrogen peroxide $\left(\mathrm{H}_{2} \mathrm{O}_{2}\right)$ PBS-TX (1:100) for 15 minutes followed by 3, 5 minute washes in PBS-TX. Sections were then blocked in a 1x animal free blocker (AFB; Vector) in PBS-TX for 30 minutes and were transferred to the primary antibody (rabbit anti c-Fos, 1:5000) for two nights at room temperature. The tissue was then washed 3 times for 10 minutes in PBSTX, and incubated in the secondary antibody (anti-rabbit, 1:1000). Sectioned were washed 3 times for 10 minutes in PBSTX and then incubated in Avidin-Biotin Complex $(\mathrm{ABC})$ for 1 hour. They were then washed 3 times for 5 minutes in $0.01 \mathrm{M}$ PBS and developed in 3,3'-diaminobenzidine (DAB) until exposed. Sectioned were washed 2 times for 5 minutes in PBS, mounted, dehydrated and cover slipped.

\section{Stereology}

The number of c-Fos labelled cells in the NAc core and shell were estimated using unbiased stereological principles and the optical fractionator method. Sections were visualized using an Olympus BX51 bright field microscope with a motorized stage (Olympus Canada, Markham, ON). An Olympus U-CMAD3 camera was used to capture images. Stereo Investigator (MBF Bioscience, Williston, VT) software was used for unbiased stereological quantification. A magnification of $2.5 \mathrm{x}$ was used to trace the NAc core and shell, and a $60 \mathrm{x}$ magnification lens (oil immersion, NA 1.35) was used to count the c-Fos positive cells. Two sections per region were used per rat, with a minimum of 3 rats per group. The estimated number of c-Fos cells using weighted section thickness was calculated through Stereo Investigator. One data point per subject was calculated by taking the average cell count from each section. In order 
to produce a standardized data point across subjects, the mean estimated number of c-Fos cells was divided by the area $\left(\mathrm{mm}^{2}\right)$. Data were analyzed using a one-way ANOVA, post-hoc tests were performed if significant group differences were found.

\section{Golgi Cox Staining}

The other hemisphere from subjects were fixed for seven days in a potassium dichromate, mercuric chloride and potassium chromate solution (Golgi fix solution). Brains were washed in $\mathrm{dH}_{2} 0$ for 4 hours, 3 hours, overnight and then cryoprotected in 10\% sucrose for 8 hours, 20\% sucrose overnight and $30 \%$ sucrose for a minimum of 4 days.

Using a Vibratome, the brains were sectioned at $200 \mu \mathrm{m}$, placed on gelatinized slides, and stored in a dark, humidified box for 24 hours. Sections were washed with $\mathrm{DH}_{2} \mathrm{O}$ for 1 minute, immersed in 28\% Ammonium Hydroxide for 40 minutes and rinsed in $\mathrm{DH}_{2} \mathrm{O}$ for 1 minute. They were then submerged in Kodak film fix A (diluted 1:1 with $\mathrm{DH}_{2} 0$ ) for 40 minutes, and rinsed in $\mathrm{DH}_{2} \mathrm{O}$ for 1 minute two times. They were then immersed in $50 \%, 70 \%$ and $95 \%$ ethanol for 1 minute each. The solutions from this point on were desiccated with type $3 \mathrm{~A}$ molecular sieve, $1 / 16$ " pellets. The slides were immersed three times in $100 \%$ ethanol for 5 minutes, and then immersed in 33\% ethanol, 33\% Clearene and 33\% chloroform solution for 10 minutes. They were then submerged in a Clearene solution for 30 minutes. Slides were then cover slipped with Permount mounting medium and placed in a desiccated box for a minimum of 4 days before analysis.

\section{Morphological analysis}

Neurolucida software (MBF Bioscience Inc., Williston, VT) was used to trace MSN dendrites at 100x magnification using an Olympus BX51 microscope. A total of 3 neurons from the NAc were selected for each rat. Only rats pretreated with MK-801, flupenthixol or saline and 
given an acute injection of saline were used for analysis. Three dendrites per neuron were selected, each with a minimum length of $200 \mathrm{~mm}$. Spine subtypes have been classified as stubby, mushroom, thin, filopodia (Peters \& Kaiserman-Abramof, 1970; Garcia-Lopez, Garcia-Marin \& Freire, 2006) and can be differentiated based on shape (Jedynak et al., 2007; Harris et al., 1992). Mushroom and stubby spines have a head diameter $>0.055 \mathrm{um}$, filopodia and thin spines have a head diameter $<0.055 \mathrm{um}$. Mushroom and filopodia spines have a discernible neck, where as thin and stubby spines do not. Spine density was calculated by averaging the total spine count divided by the total length of each dendrite per neuron. Data were analyzed using a one-way ANOVA, post-hoc tests were performed if significant group differences were found. 
Results

\section{Operant Acquisition}

Two-way repeated measures ANOVAs were conducted on all dependent variables using day as the within factor and treatment as the between factor. Early and late treatment groups were analyzed separately.

\section{Early Treatment}

Analysis of the mean number of active lever presses per day (Figure 1a) revealed a main effect of day $[\mathrm{F}(4,116)=33.65, \mathrm{p}<.000]$, but no main effect of treatment $[\mathrm{F}(2,29)=2.062), \mathrm{p}=$ $0.145]$ and no day $x$ treatment interaction $[F(8,116)=1.394, p=.206]$. Analysis of the mean number of inactive lever presses per day (Figure $1 \mathrm{~b}$ ) revealed a main effect of day $[\mathrm{F}(4,116)=$ $4.988, \mathrm{p}<0.001]$, but no main effect of treatment $[\mathrm{F}(2,29)=1.574, \mathrm{p}=0.224]$ and no day $\mathrm{x}$ treatment interaction $[F(8,116)=20.717, p=0.672]$.

Analysis of the mean number of port entries per day (Figure 1c) revealed a main effect of day $[F(4,116)=13.207, p<0.001]$, but no main effect of treatment $[F(2,29)=2.343, p=0.114]$ and no day $\mathrm{x}$ treatment interaction $[\mathrm{F}(8,116)=.918, \mathrm{p}=0.504]$. Analysis of mean locomotor activity per day (Figure 1d) revealed no main effect of day $[F(4,116)=1.195, \mathrm{p}=0.317]$, but a main effect of treatment $[\mathrm{F}(2,29)=11.428, \mathrm{p}<0.001]$ and a significant day $\mathrm{x}$ treatment interaction $[F(8,116)=3.329, \mathrm{p}<0.01]$. Tukey post-hoc tests on the effect of treatment revealed that group pretreated with flupenthixol showed significantly higher locomotor activity than the group treated with saline $(\mathrm{p}<0.01)$ and the group treated with MK-801 $(\mathrm{p}<0.001)$. 


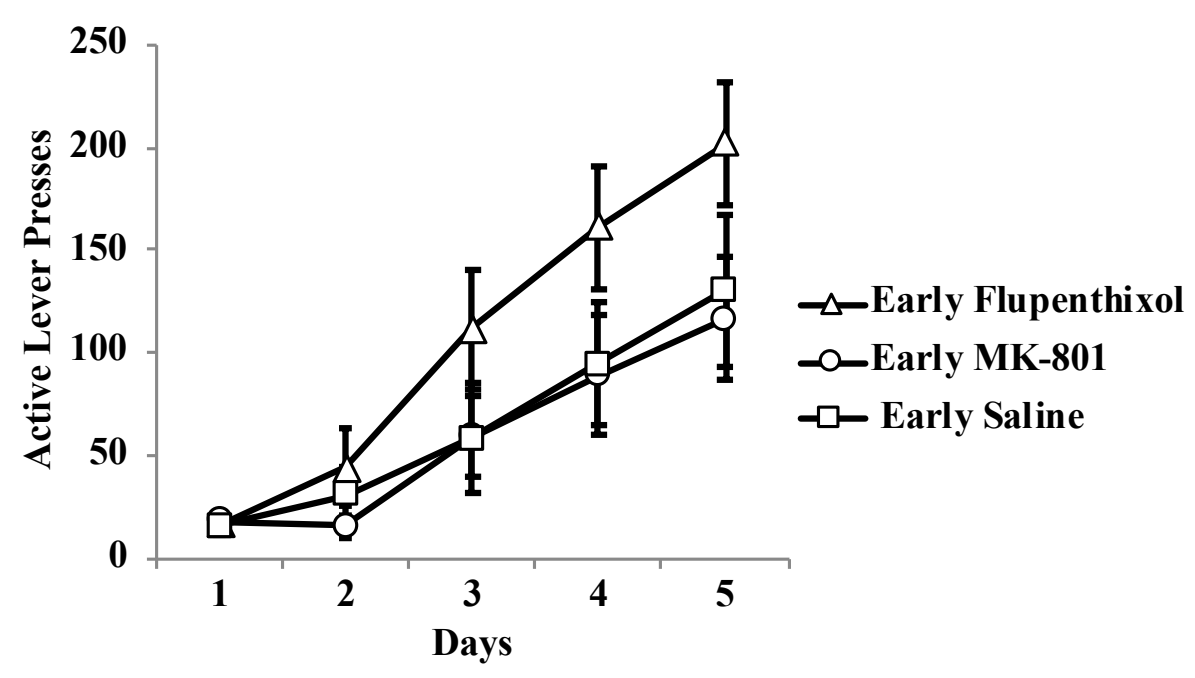

Figure 1a. Total active lever presses for chocolate pellets (FR2) during 30 minute acquisition sessions (mean \pm SEM). No group differences were found. 


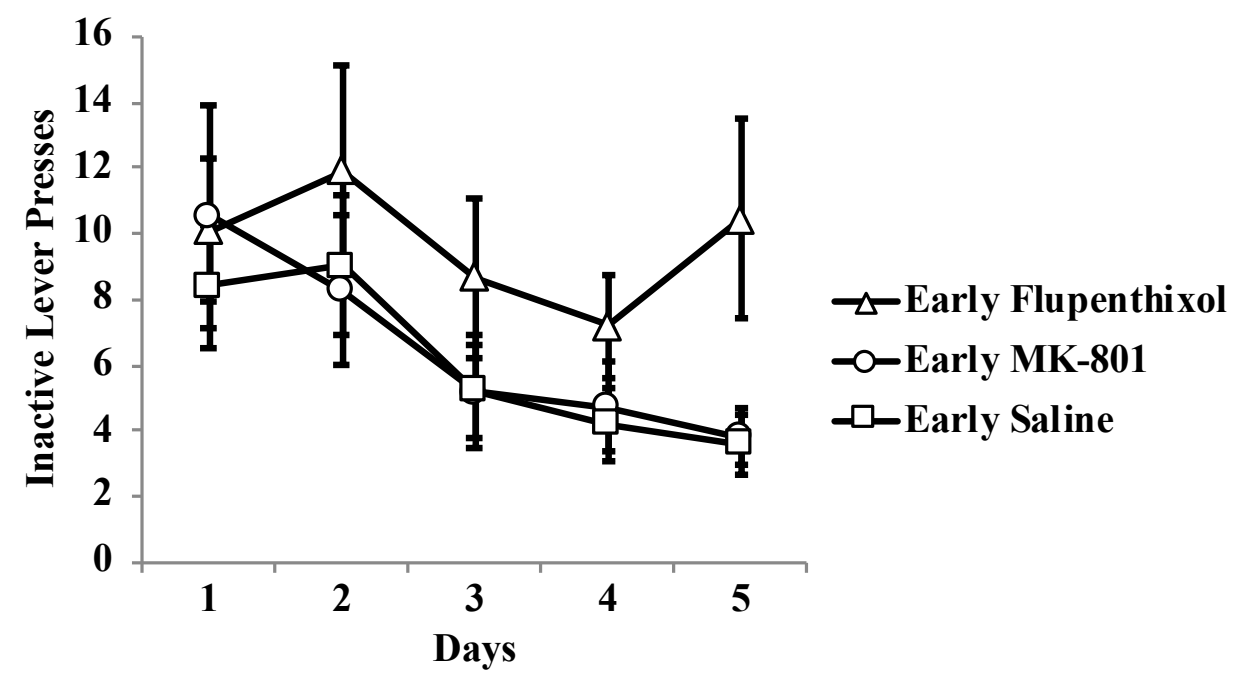

Figure 1b. Inactive lever presses during acquisition sessions (mean \pm SEM). No group differences were found. 


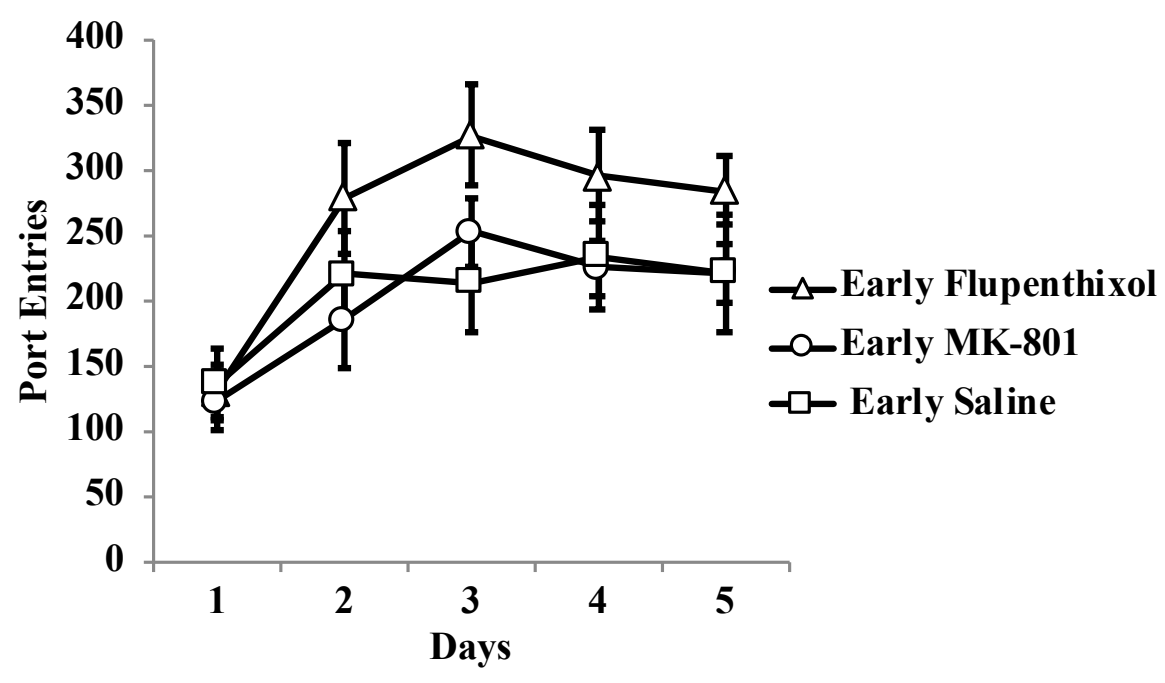

Figure 1c. Total port entries during acquisition sessions (mean \pm SEM). No group differences were found. 


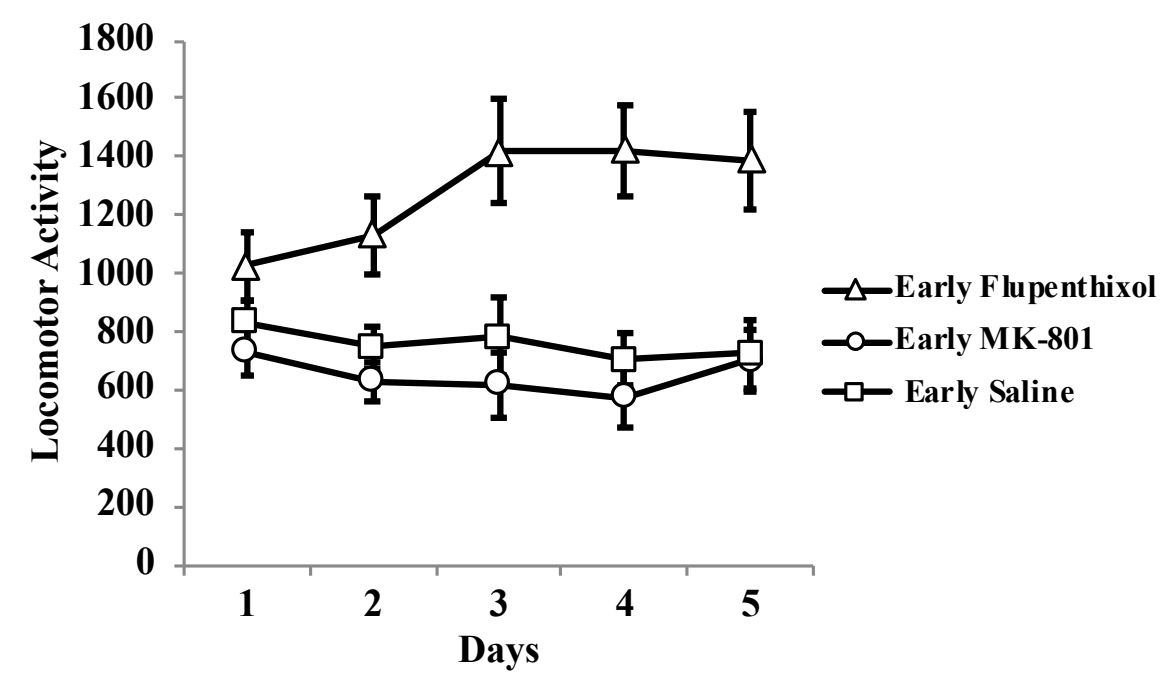

*

Figure 1d. Total locomotor activity during acquisition (mean \pm SEM). The group pretreated with flupenthixol showed significantly higher levels of locomotor activity compared to both the saline $(\mathrm{p}<0.01)$ and the MK-801 $(\mathrm{p}<0.001)$ groups. 


\section{Late Treatment}

Analysis of mean number of active lever presses per day (Figure 2a) revealed a main effect of day $[F(4,112)=27.942, p<0.001]$, a main effect of treatment $[F(2,28)=9.058, p<$ $0.001]$ and a significant day $\mathrm{x}$ treatment interaction $(\mathrm{F}(8,112)=6.711, \mathrm{p}<0.001)]$. Tukey posthoc tests on the treatment effect revealed the group treated with MK-801 pressed the active lever significantly more than the group treated with flupenthixol $(\mathrm{p}<0.001)$.

Follow up one-way ANOVAs on each day were conducted. A one-way ANOVA on day 3 revealed a main effect of treatment $[\mathrm{F}(2,30)=6.786, \mathrm{p}<0.01]$. Tukey post-hoc tests revealed that the group treated with MK-801 pressed the active lever significantly more than groups treated with saline $(p<0.05)$ and the group treated with flupenthixol $(p<0.01)$. On day 4 , a oneway ANOVA revealed a main effect of treatment $[\mathrm{F}(2,30)=6.434, \mathrm{p}<0.01]$. Tukey post-hoc tests revealed that the group treated with flupenthixol pressed significantly less than the group treated with saline $(\mathrm{p}<0.05)$ or MK-801 $(\mathrm{p}<0.01)$. On day 5 , a main treatment effect was found $[F(2,30)=12.622, p<0.001]$, with the flupenthixol group showing less presses than the groups treated with saline $(\mathrm{p}<0.05)$ or MK-801 $(\mathrm{p}<0.01)$.

Analysis of the mean number of inactive lever presses per day (Figure $2 \mathrm{~b}$ ) revealed a main effect of day $[\mathrm{F}(4,112)=3.942, \mathrm{p}<0.01]$, but no main effect of treatment $[\mathrm{F}(2,28)=3.106$, $\mathrm{p}=.060]$ and no day $\mathrm{x}$ treatment interaction $[\mathrm{F}(8,112)=.548, \mathrm{p}=0.818]$.

Analysis on mean number of port entries per day revealed a main effect of day $[F(4,112)=9.926, p<0.001$, a main effect of treatment $[F(2,28)=10.581, p<0.01]$, and a day $x$ treatment interaction $[\mathrm{F}(8,112)=2.821, \mathrm{p}<0.01]$. Tukey post-hoc tests revealed that the group treated with MK-801 had significantly more port entries than the group treated with flupenthixol $(p<0.01)$. Analysis of locomotor activity per day revealed a main effect of day $[F(4,112)=$ 
2.558, $\mathrm{p}<0.05]$, a main effect of treatment $[\mathrm{F}(2,28)=20.253, \mathrm{p}<0.01]$ and a day $\mathrm{x}$ treatment interaction $[\mathrm{F}(8,112)=2.47, \mathrm{p}<0.05]$. Tukey post-hoc tests revealed that the group treated with flupenthixol showed significantly less locomotor activity than the groups treated with saline or MK-801 $(\mathrm{p}<0.001)$.

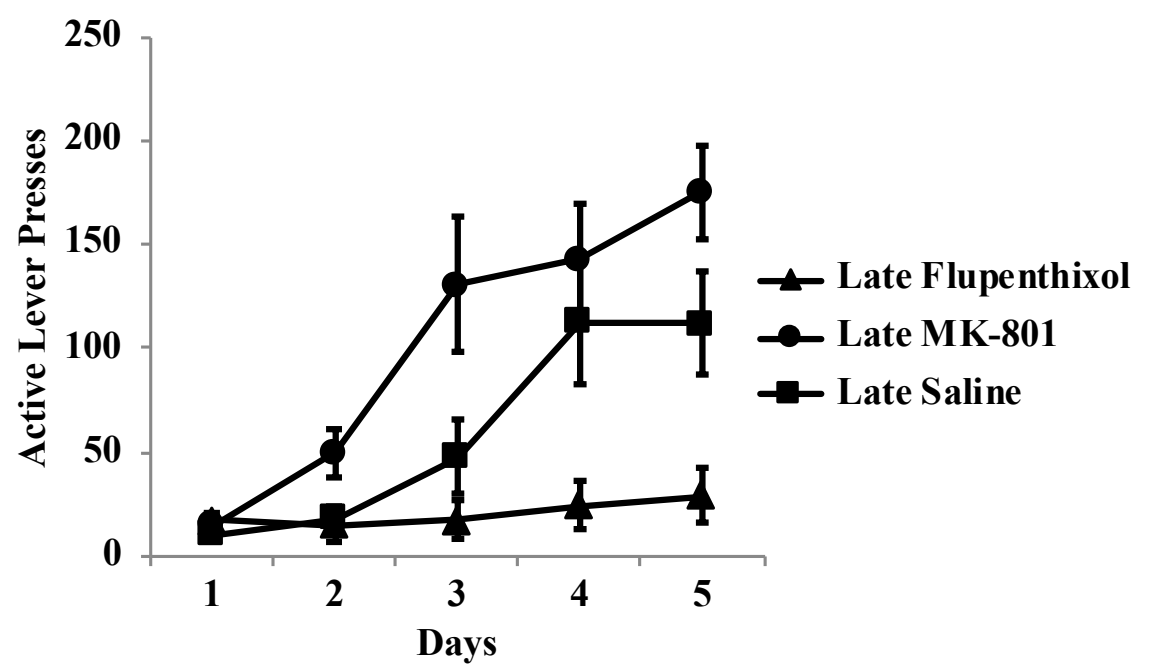


Figure 2a. Total active lever presses for chocolate pellets (FR2) during acquisition sessions (30 minutes each) (mean $\pm \mathrm{SEM})$. On day 3 , the group that received an injection of MK801,15 minutes prior to each acquisition session pressed the active lever significantly more than the groups treated with saline $(\mathrm{p}<0.05)$ or flupenthixol $(\mathrm{p}<0.01)$. On day 4 and 5 , the group treated with flupenthixol pressed significantly less than the group treated with saline $(\mathrm{p}<0.05)$ or MK-801 $(\mathrm{p}<0.01)$. 


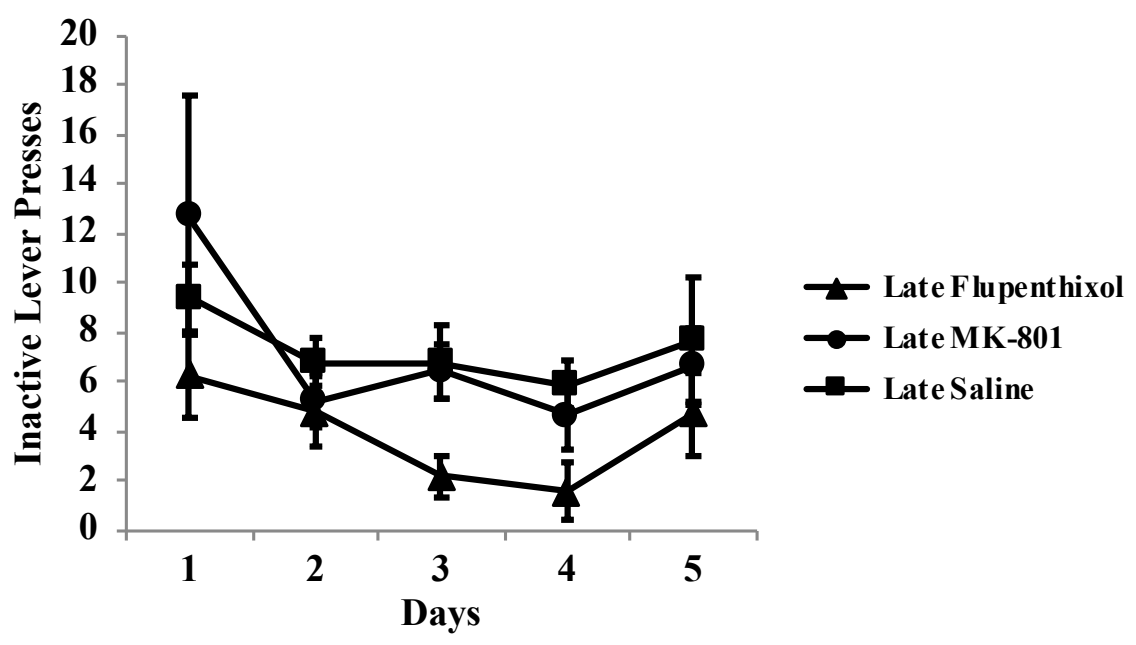

Figure $2 b$. Inactive lever presses during acquisition sessions (mean \pm SEM). No group differences were reported. 


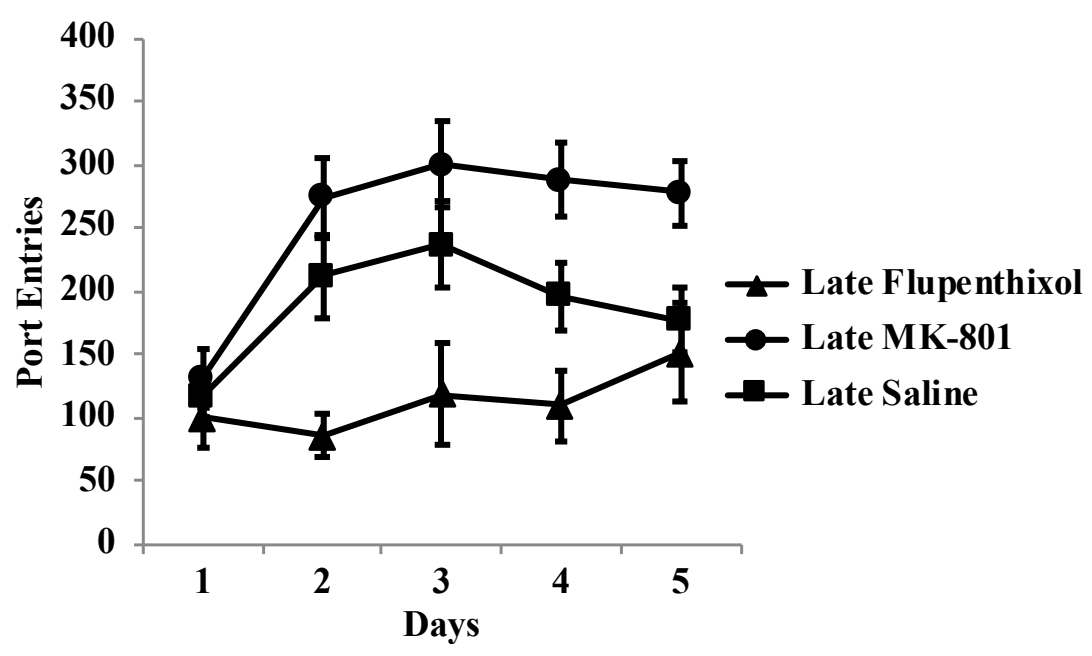

Figure 2c. Total port entries during acquisition (mean \pm SEM). The group treated with MK-801, 15 minutes prior to each acquisition session showed significantly more port entries than the group treated with flupenthixol $(\mathrm{p}<0.01)$.

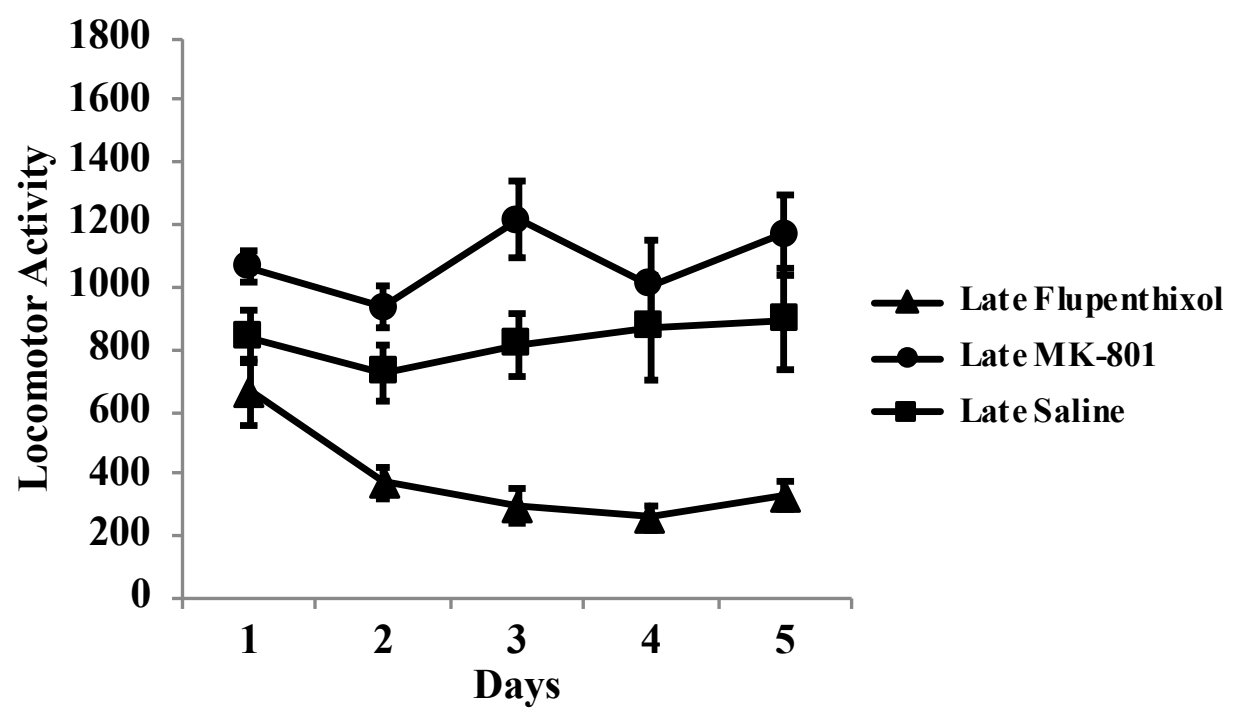


Figure $2 \mathrm{~d}$. Locomotor activity during acquisition (mean \pm SEM). The group injected with flupenthixol 15 minutes prior to each acquisition session showed significantly less locomotor activity than the groups treated with saline or MK-801 $(\mathrm{p}<0.001)$.

\section{C-Fos quantification}

\section{Dopamine}

The average cellular density [mean cell count/ volume $\left.\left(\mu \mathrm{m}^{3}\right)\right]$ for each treatment group was calculated. Data are represented as percent change from control [(average cellular density of individually treated rats/ group average of pretreated and acutely injected with saline) * 100]. Rats were pretreated with saline or flupenthixol during preadolescence and received an injection 
of apomorphine or saline at test. A one-way ANOVA on the density of c-Fos labeling in the NAc core (Figure $4 a$ ) revealed a main effect of treatment $[F(2,12)=9.114, p<0.01]$. Tukey post-hoc tests revealed a higher density of c-Fos labeling in the group pretreated with flupenthixol and injected with apomorphine at test compared to the group pretreated with flupenthixol and treated with saline at test $(\mathrm{p}<0.05)$.

A one-way ANOVA on the density of c-Fos labeling in the NAc shell (Figure $4 \mathrm{~b}$ ) revealed a main effect of treatment $[\mathrm{F}(2,12)=4.243, \mathrm{p}<0.05]$. Tukey post-hoc tests revealed a higher density of c-Fos labeled cells in the group pretreated with flupenthixol and injected with apomorphine at test compared to the group pretreated with flupenthixol and treated with saline at test $(\mathrm{p}<0.05)$.

Flu-Saline 


\section{Saline- Apo}
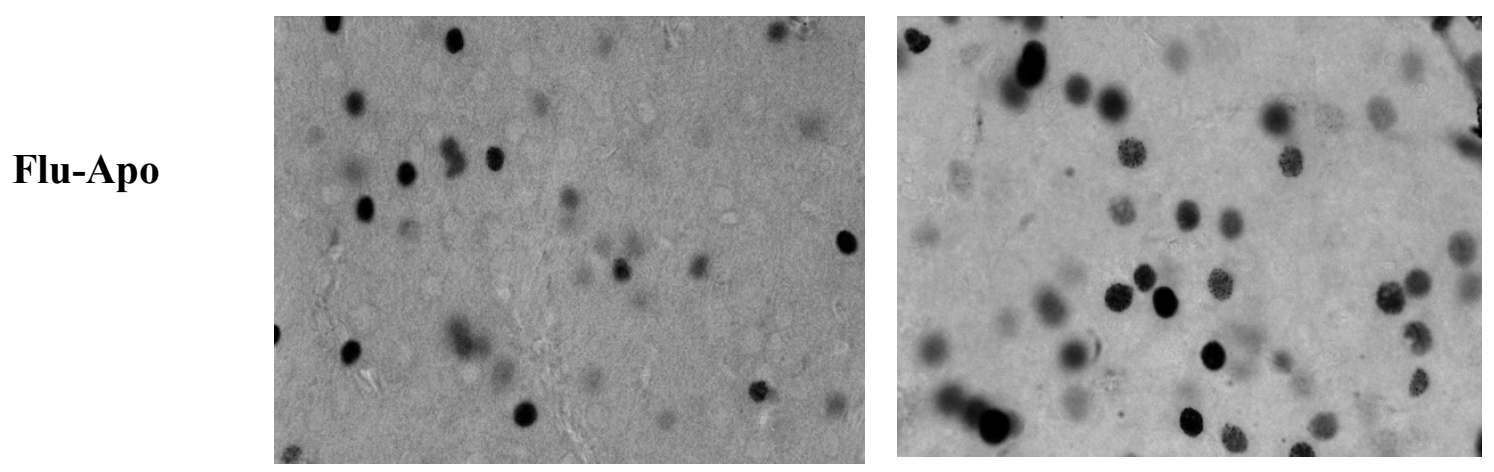

Figure 3. Representative images of c-Fos for the dopamine treatment groups in the NAc (60x)

Core

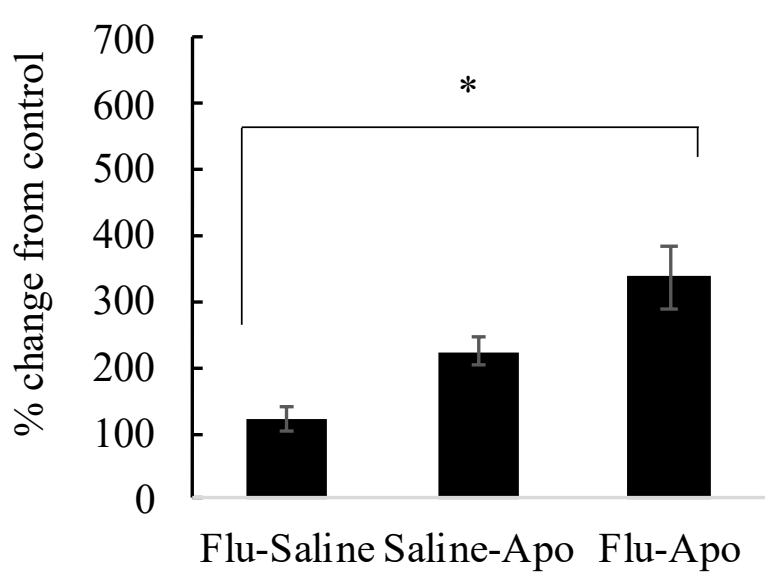

Shell

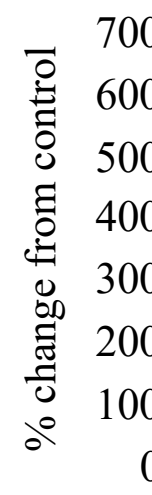

Flu-Saline Saline-Apo Flu-Apo 
Figure $4 \mathrm{a} \& \mathrm{~b}$. Percent change from control of the average cellular density [mean cell count/ volume $\left.\left(\mu \mathrm{m}^{3}\right)\right]$ of $\mathrm{c}-$ Fos labeling in the core and shell (mean \pm SEM). The group pretreated with flupenthixol that received an acute injection of apomorphine at test showed significantly more cFos labeling in the core and the shell than the group pretreated with flupenthixol that received an acute injection of saline $(\mathrm{p}<0.05)$.

\section{NMDA}

Rats were pretreated with saline or MK-801 during preadolescence and received an injection of TZG or saline at test. A one way ANOVA on the density of c-Fos labeling in the NAc core (Figure 5a) and shell (Figure 5b) revealed no main effects of group $[F(2,12)=3.650, p=0.065]$; $[\mathrm{F}(2,12)=.650, \mathrm{p}=0.543]$

\section{Core}

Shell 
MK-801-Saline

Saline-TZG
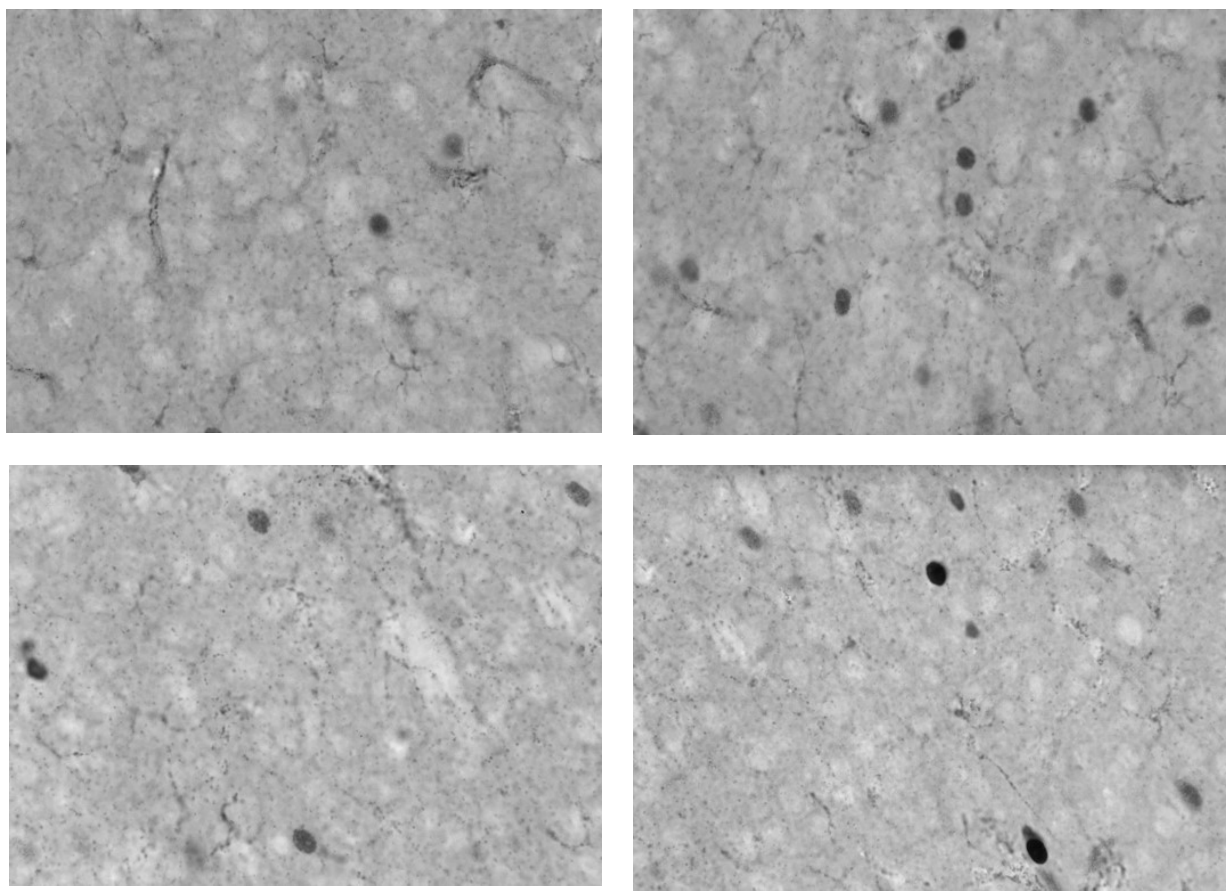

Figure 5. Representative images of c-Fos for the NMDA treatment groups in the NAc (60x) 
Core

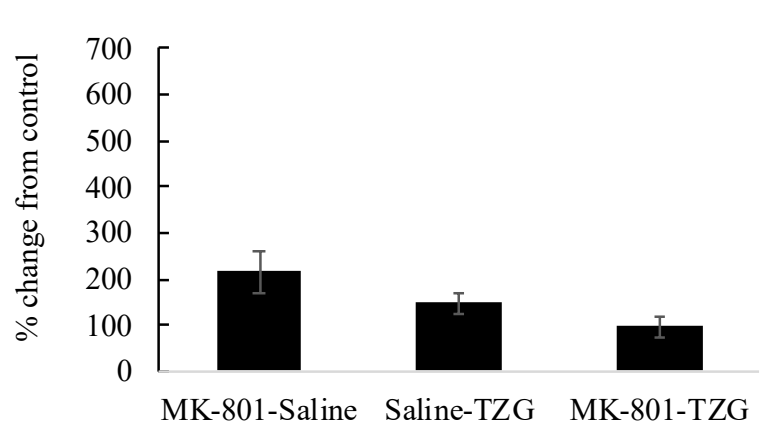

Shell

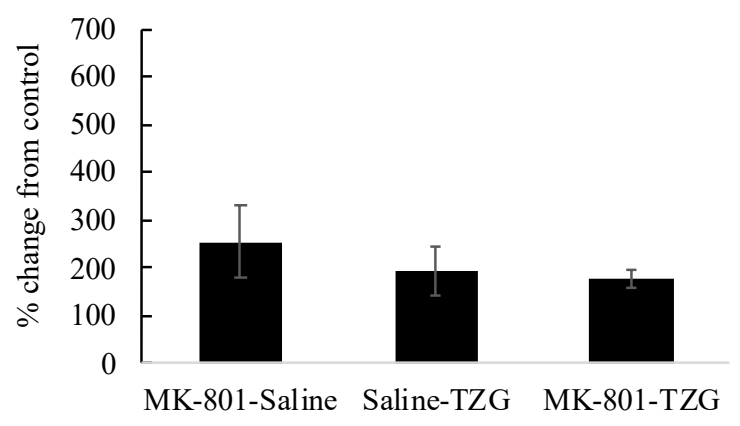

Figure $6 \mathrm{a} \& \mathrm{~b}$. Percent change from control of the average cellular density [mean cell count/ volume $\left.\left(\mu \mathrm{m}^{3}\right)\right]$ of c-Fos labeling in the core and shell (mean \pm SEM). No group differences were found. 


\section{Spine density quantification}

A one-way ANOVA on total spine density (Figure 5a) revealed no main effect of treatment $[\mathrm{F}(2,6)=0.643]$. A two-way repeated measures ANOVA on spine density subtype (Figure $6 b$ ) revealed a main effect of spine subtype $[\mathrm{F}(3,35)=23.407, \mathrm{p}<0.01]$, but no main effect of treatment $[F(2,35)=0.765]$. Tukey post hoc tests revealed significantly more thin spines than stubby, mushroom and filopodia $(\mathrm{p}<0.01)$ and more stubby spines than mushroom and filopodia $(\mathrm{p}<0.01)$.

Saline

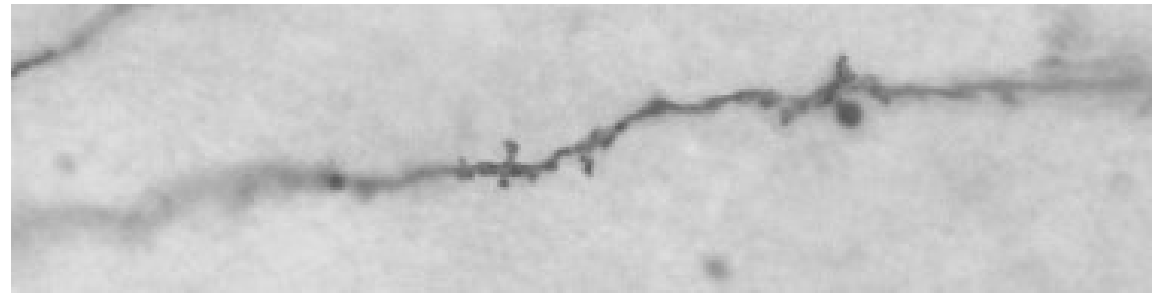

MK-801

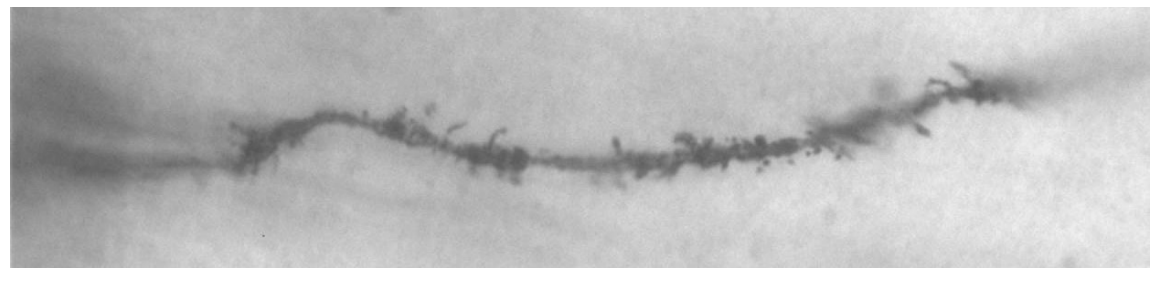

Flupenthixol

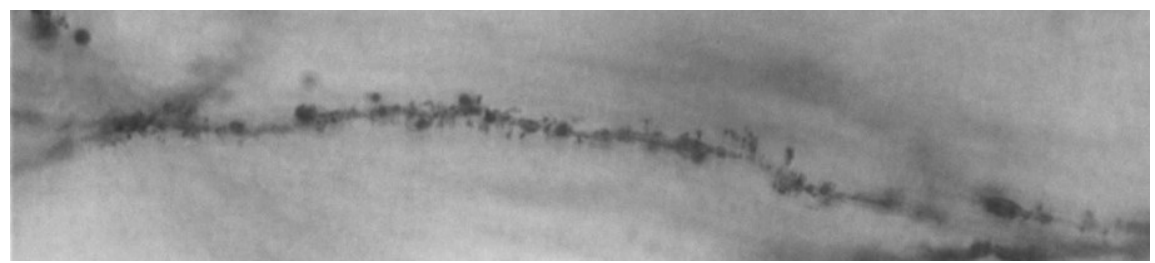

Figure 7. Representative images of dendritic spines in the NAc at 100x. 

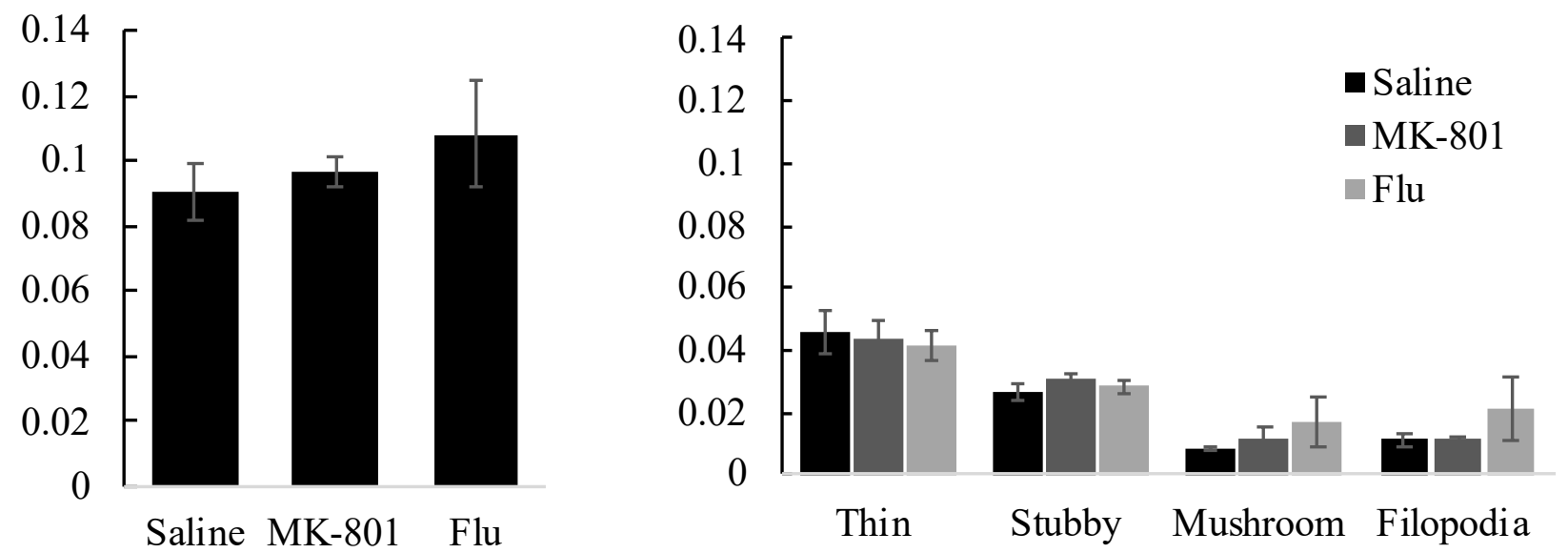

Figure $8 \mathrm{a} \& \mathrm{~b}$. Total spine density [total number of spines/total length $(\mu \mathrm{m})$ ] and spine subtypes [number of each spine subtype/total length $(\mu \mathrm{m})]$ in the NAc (mean \pm SEM). A main effect of spine subtype was found $(\mathrm{p}<0.01)$, but no main effect of treatment. 


\section{Discussion}

\section{Summary}

Rats were treated with MK-801, flupenthixol or saline during a preadolescent period (P18-24) and were tested in an operant conditioning procedure after adolescence. Early treatment with the dopamine receptor antagonist, flupenthixol, increased locomotor activity and lever pressing during the post-adolescent testing phase (Fig 9). Early treatment with the NMDAr antagonist, MK-801, did not result in any overt behavioral alterations during the test. To examine the behavioral changes under the influence of the drug, separate groups of rats were treated with flupenthixol or MK-801 prior to each acquisition session. In this case, flupenthixol $(0.25 \mathrm{mg} / \mathrm{kg}$; same dose as used during preadolescent phase) decreased lever pressing and locomotor activity (Fig 9). While early MK-801 had no effect on any behavioral measure, late MK-801 was associated with an increase in bar pressing, port entries and locomotor activity (Fig 9).

Immunohistochemical and morphological analyses were conducted to provide a potential explanation of the behavioural results. Two possible hypotheses were explored to assess what form of developmental plasticity contributed to the behavioural outcomes. The structural plasticity hypothesis stated that early treatment with either an NMDAr antagonist or DAr antagonist would impede the development of neurons in the NAc and this would manifest as reduced spine densities. The synaptic plasticity hypothesis stated that early treatment with MK801 or flupenthixol would desensitize NMDA or DA receptors, respectively, during adolescence. This would manifest as reduced c-Fos labeling following an injection of the NMDAr agonist TZG or the dopamine receptor agonist apomorphine. There was no evidence of structural differences in the NAc between treatment groups, possibly indicating that behavioural 
differences seen were not due to morphological changes. Elevated c-Fos staining was found after an acute challenge with the dopamine agonist apomorphine in both the saline-apo and flupenthixol-apo group. This increase in cellular activity was higher in the flupenthixol group compared to controls, indicating a sensitized response at DA receptors. It is likely that the elevated bar pressing and locomotor activity as seen in the early flupenthixol group was due to sensitized DA receptors in the NAc (Fig 9). The NMDA agonist, TZG, slightly elevated cellular activity in both the saline-TZG and MK-801-TZG group. Interestingly basal c-Fos levels were equal in the MK-801-saline group compared to TZG-induced levels.

Comparing total active lever presses and total locomotor activity with the c-Fos results (Figure 9) we can see that early flupenthixol increased activity and apomorphine-induced c-Fos. This provides support for a dopaminergic sensitization hypothesis whereby preadolescent treatment with a DA antagonist sensitized dopaminergic receptors in the NAc and elevated operant conditioning in adolescence.

Total Presses Over 5 Days
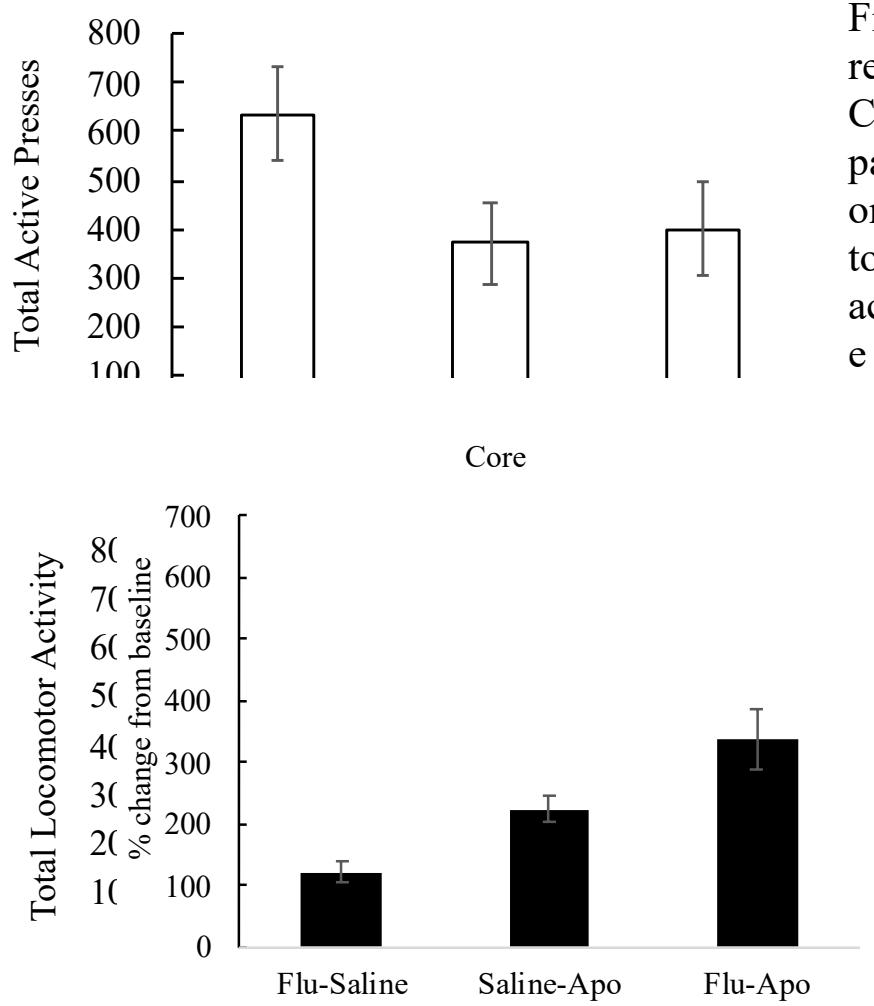

Total Presses Over 5 Days

Figu

re 9.
Com
paris
on of
total
activ
e

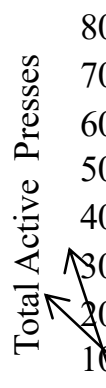

800

00

600

500

on of

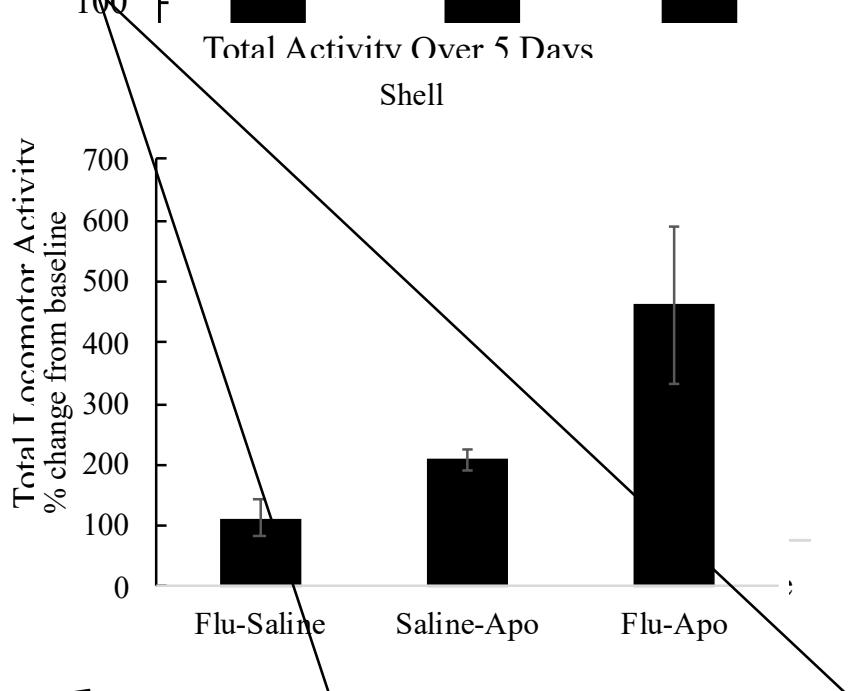


lever presses and total locomotor activity over 5 days of acquisition with c-Fos results after apomorphine.

\section{Dopamine}

Early flupenthixol $(0.25 \mathrm{mg} / \mathrm{kg})$ increased lever pressing and activity during the adolescent test (Fig. 9), whereas flupenthixol treatment during the adolescent test $(0.25 \mathrm{mg} / \mathrm{kg})$ decreased both. One possible explanation for the divergent treatment effects is that early treatment with flupenthixol sensitized DAr. During operant conditioning, DA in the NAc is first released in response to the reward then shifts to the cue predictive of the reward (Schultz, Dayan \& Montague, 1997; Day et al., 2007). Once the cue becomes conditioned and after presentation of a CS, mesolimbic DA neurons activate (Waelti, Dickinson \& Schultz, 2001) and release DA into the NAc (Cheng, Bruin \& Feenstra, 2003; Day et al., 2007; Stuber et al., 2008). Likewise, NAc DAr blockade impairs instrumental response to a CS (Wakabayashi, Fields \& Nicola 2004; Nicola, 2010). Given that extracellular DA in the NAc increases locomotor activity (Pijnenburg \& van Rossum, 1973) and lever pressing (Salamone et al., 1990; Wyvell \& Berridge, 2000), chronic early treatment with flupenthixol may have sensitized DAr in the NAc. This would increase the efficacy of the CS-induced DA release (Sandstrom, Nelson \& Bruno, 2003); either due to an increase in the number of postsynaptic DAr receptors or an increase in the sensitivity of DAr present (Nielsen et al., 1973)

We tested the hypothesis that preadolescent flupenthixol treatment altered DAr sensitivity by challenging subjects with an acute injection of the DA agonist apomorphine during adolescence (P40). This day was chosen because it was equivalent to the first day of operant acquisition, allowing us to infer what may be happening at the level of the synapse during the operant task. The early flupenthixol and the early saline groups were given an acute injection of 
apomorphine $(3 \mathrm{mg} / \mathrm{kg}, \mathrm{s.c})$. This dose was chosen because it increases locomotor activity (Castro et al., 1985; Fredriksson \& Archer, 2000) and it is a threshold dose in between $2 \mathrm{mg} / \mathrm{kg}$ (Cole et al., 1992) and 4mg/kg (Wirtshafter, 2000) that increase c-Fos levels in the striatum. While low (1mg/kg) (Rebec et al., 1979; Deutch \& Dunman, 1996) and high doses (5mg/kg) (Pennypacker, Zhang \& Hong, 1992; Filipkowski, Rydz \& Kaczmarek., 2001; Saint Marie et al., 2006) resulted in inconsistent levels of c-Fos (Filipkowski, Rydz \& Kaczmarek., 2001), the medium dose consistently increases c-Fos.

Elevated apomorphine-induced c-Fos levels were found in the NAc in both the flupenthixol-apo and saline-apo group. These results are consistent with previous research demonstrating increased locomotor activity and NAc activation following apomorphine (Steiner \& Gerfen, 1994; Cenci et al., 1992) or other DA agonists (Kalivas \& Duffy, 1990; Johnson \& Glick, 1993; Scofield et al., 2016). This increase in cellular activity was higher in the earlyflupenthixol treated group compared to the early-saline treated control, indicating potential dopaminergic sensitization in the early flupenthixol group. These results corroborate the behavioural results that revealed increased locomotor activity and elevated lever presses in the early-flupenthixol group and support the hypothesis that increased locomotor activity and total active lever presses were due, in part, to sensitized dopaminergic receptors in the NAc.

In a previous study, rats were pretreated with flupenthixol $(2.5 \mathrm{mg} / \mathrm{kg}$, orally) for 12 days and tolerance towards the pharmacological properties of the DAr antagonist were tested following various time periods of withdrawal (Nielsen et al., 1974). On the test day, pretreated rats and controls were first given an acute injection of flupenthixol followed by apomorphine. Flupenthixol pretreated rats exhibited tolerance to apomorphine; higher doses of acute flupenthixol were needed to block apomorphine-induced stereotypy. This effect was present for 
up to 21 days following withdrawal, and highest 3 days after. In the present study, apomorphine induced c-Fos levels were higher in the flupenthixol group compared to saline group. Considering that the time period of withdrawal in the present study was 7 days, it is likely that similar synaptic processes occurred.

After acute DAr blockade and withdrawal, there is increased sensitivity to apomorphine (Nielsen et al., 1973). Studies have shown that after long-term treatment with the antipsychotic and D2 receptor antagonist haloperidol, rats and humans show increased locomotor activity and elevated densities of D2 receptors (see Review Seeman et al., 2006). Indeed, patients with schizophrenia who have taken antipsychotics have been shown through post-mortem studies (Seeman, 1987) and PET scans (Nordstrom et al.,1995; Tune et al., 1993) to have increased D2 receptor density. Chronic treatment with flupenthixol has been demonstrated to increase D2 receptor density (Hess, Norman \& Creese, 1988). Flupenthixol in vitro has an equal affinity for D1 and D2 receptors, but in vivo preferentially interacts with D2 receptors which may explain why D2, but not D1 receptor density increased (Hess, Norman \& Creese, 1988). Coadministration of both D1 and D2 receptor antagonists increased apomorphine-induced locomotion and D2 receptor density (Braun, Laruelle \& Mouradian, 1996).

Morphological analysis revealed no differences in structural changes in the NAc between the early saline and early flupenthixol groups. This suggests that preadolescent DAr blockade does not produce long-term structural changes in the NAc. In another study preadolescent rats (P27) were administered neurotoxin 6-hydroxydopamine (6-OHDA) in the medial forebrain bundle resulting in depletions of DA in striatum (Sandstrom, Nelson \& Bruno, 2003). A week post-surgery locomotor activity and basal DA levels in the NAc were measured. Compared to aged-matched controls, lesioned rats had similar locomotor activity and DA levels despite having 
a $95 \%$ reduction in DA producing cells. Adults rats that were lesioned showed an equal depletion in DA producing cells one week post 6-OHDA administration, yet exhibited severe motor deficits as well as an $80 \%$ reduction in basal DA levels. Based on these results and our current study there seem to be compensatory mechanisms during preadolescence following DAr blockade or lesion.

As previously stated, extracellular DA in the NAc is required for operant acquisition, therefore blocking DAr through receptor occupation would impair this process. As expected, late treatment with flupenthixol $(0.25 \mathrm{mg} / \mathrm{kg})$ decreased locomotor activity and total lever pressing. This, along with other research, shows that the immediate effect of dopamine receptor blockade is to reduce locomotor activity and bar pressing (Floresco., Tse \& Ghods-Sharifi, 2008). The same dose $(0.25 \mathrm{mg} / \mathrm{kg})$ decreased the frequency of high effort responding (FR10) but did not affect the latency towards the lever (Floresco, Tse \& Ghods-Sharifi, 2008). A lower dose $(0.125 \mathrm{mg} / \mathrm{kg})$ did not have immediate effects on locomotor activity yet decreased bar pressing (Floresco, Tse \& Ghods-Sharifi, 2008) suggesting that DAr blockade impairs lever pressing ability independently from the motoric impairing effects. Similarly, the lower dose $(0.125 \mathrm{mg} / \mathrm{kg})$ did not decrease lever pressing performance when an instrumental task was already learned (Dickinson,Smith \& Mirenowicz, 2000). When there is choice between a large reward with a delay and a small immediate reward, $0.5 \mathrm{mg} / \mathrm{kg}$, but not $0.25 \mathrm{mg} / \mathrm{kg}$ effects the likelihood of subjects choosing the latter (Wade, Wit \& Richards, 2000).

Another dopamine antagonist, Pimozide, affects operant conditioning in a dosedependent manner, whereby a lower dose decreased acquisition independently from locomotor activity or lever pressing ability (Yokel \& Wise 1976; Wise \& Schwartz, 1981). Similarly, both a D1 and D2 receptor antagonist decreased lever pressing, but not food consumption (Salamone et 
al., 2002). Others have found that the D2 receptor antagonist haloperidol suppressed lever pressing for food (Salmone et al., 1991) and decreased high effort choices for a large reward in a T-maze (Denk et al., 2005). In a Pavlovian procedure in which a stimulus (lever) is followed by a reward (sucrose) it has been observed that some subjects will find the lever itself rewarding (sign-trackers) while some subjects will go to the port to wait for the reward (goal-trackers). Low doses of haloperidol disrupt sign-tracking, but not goal-tracking, demonstrating that DAr antagonism may disrupt the process by which a cue or CS becomes rewarding (Danna \& Elmer, 2010).)

In operant conditioning, port entries are a behavioural measure used to directly assess reward-seeking behaviour and indirectly assess frequency of reward received. In the present study, late flupenthixol treatment $(0.25 \mathrm{mg} / \mathrm{kg})$ decreased port entries. However, it is difficult to discern whether the low port entries were due to an inability to enter the port or due to lack of reward-seeking behaviour. A higher dose of flupenthixol $(0.5 \mathrm{mg} / \mathrm{kg})$ did not impair port entries when a reward was present (Wade, Wit \& Richards, 2000), therefore it is probable that the lower dose $(0.25 \mathrm{mg} / \mathrm{kg})$ in the current study did not impair the ability to enter the port. Rather, the decrease in port entries was likely due to less reward present and not ability to obtain the reward.

Taken together, these results demonstrate and highlight two points: when studying the effects of an antagonist, it is 1) difficult to distinguish whether the blockade interferes with the learning process itself or interferes with a behaviour required to demonstrate learning (Beninger, 1983) and 2) the dose and subtype of the receptor help dissociate learning processes from motor ability. It is evident that a varying degree of DAr occupation is needed for certain aspects of operant acquisition and performance. A wider dose range in the current study may have helped dissociate locomotor activity from lever pressing and port entries. 


\section{NMDA}

In the present study, early MK-801 $(0.05 \mathrm{mg} / \mathrm{kg})$ did not produce a learning deficit; no group differences were found in active lever pressing, inactive lever pressing or port entries during acquisition between the early MK-801 group and saline control. Late MK-801, on the other hand $(0.05 \mathrm{mg} / \mathrm{kg})$, enhanced acquisition and increased total port entries. The early treatment results are surprising given the importance of NMDAr in developmental plasticity (Durand, Kovalchuk \& Konnert, 1996; Ben-Ari et al., 1997) and associative learning (Chen, Hopf \& Bonci, 2010; Shiflett \& Balleine, 2011). We hypothesized that early NMDAr antagonism would decrease both structural and synaptic plasticity in the NAc and consequently impair operant learning. Morphological analysis revealed no structural changes in the NAc between early-MK-801 and saline groups. This is consistent with the behavioural results that revealed no differences during operant conditioning.

The goal of the agonist test during adolescence was to examine the influence of NMDAr antagonism during preadolescence on later receptor function. The NMDA agonist TZG slightly elevated c-Fos expression in the NAc in both the saline-TZG and MK-801-TZG groups, potentially indicating increased cellular activity compared to control in response to ligand binding. Previous research found TZG (Rogers et al., 2005; Inada et al., 2007) and NMDA increased c-Fos expression (Sonnenberg et al., 1989; Lerea, Butler \& McNamara, 1992) and increased Ca2+ (Lerea, Butler \& McNamara, 1992) in neural regions including the NAc (Inada et al., 2007; Dragunow \& Faull, 1990; Duncan et al., 1998). No differences were found between rats pretreated with MK-801 and saline in response to TZG which is consistent with the 
behavioural data that demonstrated similar lever pressing, port entries and locomotor activity in both groups.

Interestingly, rats pretreated with MK-801 and injected with saline had the highest levels of c-Fos labeling. This is consistent with previous research demonstrating increased c-Fos levels in the hippocampus after repeated injections with the NMDAr antagonist ketamine followed by a 14 day washout period (Keilhoff et al., 2004). One possible explanation for these results is a supersensitization of NMDAr where LTP is more easily induced. Therefore, neutral stimuli or a saline injection may produce increased c-Fos levels that would not normally occur due to a lowering of the threshold needed for activation (Keilhoff et al., 2004).

During development, NMDAr subunits change with an increase in NR2A subunit expression (Monyer et al., 1994; see review Yashiro \& Philpot, 2008). In rats, the ratio of NMDAr containing NR2B change from $70 \%$ at P-15-P28 to $40 \%$ of adult levels at P31-P49 (Wang \& Gao, 2009). It is hypothesized that this change may affect LTP and LTD by changing the permeability of NMDAr to $\mathrm{Ca}^{2+}$ (Yashiro \& Philpot, 2008). An increase in the ratio of NR2A/NR2B at a synapse is thought to change the LTP/LTD crossover threshold making it more likely for LTD to occur.

In one study, high doses of systemic MK-801 (1mg/kg, i.p.) were injected in mice from P16 to P40 (Inta et al., 2017). C-Fos levels peaked in the hippocampus at P24 followed by lower levels at P30 and P40. It was hypothesized that MK-801 increased c-Fos levels by binding to NR2B-containing NMDAr which then disinhibited GABAergic interneurons (Gass et al., 1993; Inta et al., 2017). The differences found in MK-801 induced c-Fos expression during development may be due to NMDAr subunit changes. Indeed, following administration of the 
NR2B specific antagonist Ro 25-6981, c-Fos levels peaked at P24 and declined thereafter (Inta et al., 2017).

Changes in NMDAr subunits are partly mediated by sensory experience (Yashiro \& Philpot, 2008). During a critical period of visual development, light deprivation will influence the switch from NR2B to NR2A to occur more slowly (Nase et al.,1999; Roberts \& Ramoa, 1999) It is unclear how NMDAr antagonism in the present study would impact the developmental switch of these glutamatergic receptors. In adulthood, repeated MK-801 increases NR2B subunits in the hippocampus (Rujescu et al., 2006), which increases likelihood of LTP to occur (Barria \& Malinow, 2005; Bellone \& Lusher, 2012; Mameli et al., 2011). The rise in NR2A is activity dependent; glutamate is required to bind to NMDAr for protein synthesis to occur (Barria \& Malinow, 2005). If glutamate binding to NMDAr is necessary for NR2A production, it is possible that antagonizing these receptors may slow down this process. If early MK-801 did slow down this process, there would be a higher ratio of NR2B receptors during the agonist test compared to the saline control and an increased likelihood of LTP to occur. This may explain the NMDAr supersensitivity and increased basal c-Fos levels seen after an injection of saline (Keilhoff et al., 2004). Future studies would benefit from using western blot analyses to measure levels of protein for NMDAr subunits and compare the early-MK-801 treatment with saline controls during adolescence.

When comparing the present study to the literature, differences in behavioural outcomes after repeated MK-801 administration can be characterized in to differences in timing, dose and behavioural task. To our knowledge NMDAr blockade during this period of development (P18P24) has not been tested in an operant procedure. Previous research has demonstrated that rats pretreated with MK-801 (0.1mg/kg, twice daily) from P7-P11 exhibited severe learning deficits 
during operant acquisition in adulthood (Rapanelli et al., 2013). This is contrary to the present findings where early MK-801 (P18-P24) did not disrupt acquisition. Rapanelli et al., (2013) also demonstrated that rats treated with MK-801 $(0.1 \mathrm{mg} / \mathrm{kg}$ twice a day IP) in adulthood one week prior to operant conditioning exhibited mild learning deficits. The differences between this and the present study are likely due to both the timing and dose of the injections.

Morphological analysis revealed no structural changes in the NAc between the MK-801 and saline groups. Novak et al. (2013) characterized 60 genes during striatal development and found that during P7-P14 an early gene network that does not express striatal-specific genes was down-regulated and replaced with a mature network. This network gave immature neurons a functional identity and projection pathway. During this week, there was a rise in D1 and D2 receptors, both following the same developmental trajectory. At the end of this week MSNs found their functional identity. Repeated injections with MK-801 from P7-P11 during the time where neurons are developing their functional identify would likely have a severe impact on striatal development and associative learning. Novak et al., (2013) also found a rise in myelination genes from P14 to P17. It is possible that NMDAr antagonism after myelination (P18-P24) had less or no impact on operant conditioning compared to disrupting this developmental process at an earlier stage.

A meta-analysis of postnatal treatment with MK-801 revealed conflicting results in a number of behavioural tasks (Lim, Taylor \& Malone, 2012). Early NMDAr antagonism does not seem to effect novel object recognition in adulthood (Delacour, 1988; Stefani \& Moghaddam, 2005; Lim, Taylor \& Malone, 2012) or visual-cue performance in the Morris water maze (Gorter \& de Bruin., 1992; Nemeth et al., 2002). Postnatal MK-801 treatment impaired spatial recognition in adult rats (Gorter \& de Bruin., 1992; Nemeth et al., 2002; Su et al., 2011), but not 
in adolescent rats (Su et al., 2011). Spatial tasks may be more affected because MK-801 has a higher affinity to bind in the hippocampus compared to the cerebral cortex and striatum (Wong et al., 1986).

MK-801 $(0.05 \mathrm{mg} / \mathrm{kg})$ prior to each acquisition day enhanced acquisition and increased port entries. This is consistent with work from our lab and others that have found low doses of MK-801(0.025mg/kg and 0.05mg/kg) increased operant acquisition (Sanger \& Jackson, 1989; Gilmour et al., 2009; Smith et al., 2011) and lever pressing during extinction (Tuplin, Stocco \& Holahan, 2015; Holahan, Clarke \& Hines, 2010). In contrast, another study found no effect of low doses $(0.025 \mathrm{mg} / \mathrm{kg}$ and $0.05 \mathrm{mg} / \mathrm{kg})$ on operant acquisition (Port, Murphy, Magee \& Seybold, 1996). High doses $(0.2 \mathrm{mg} / \mathrm{kg}$ and $0.25 \mathrm{mg} / \mathrm{kg})$ consistently impair operant acquisition (Gilmour et al., 2009; Wozniak et al., 1990; Clissold, Ferkany \& Pontecorvo, 1991; Pitts et al., 2006; Smith et al., 2011; Lover-Ulecia et al., 2018; Povroznik et al., 2014). There are mixed results with moderate doses $(0.1 \mathrm{mg} / \mathrm{kg})$ with some finding a mild deficit in learning (Stephani \& Moghaddam, 2005; Pitts et al., 2006; Rapanelli et al., 2013; Smith et al., 2011; Lover-Ulecia et al., 2018) and others finding no effect (Clissold, Ferkany \& Pontecorvo, 1991; Port, Murphy, Magee \& Seybold, 1996). These conflicting results within the same doses of MK-801 are likely due to differences in test parameters (Liu et al., 2017).

The enhancing effect of late MK-801 in the current study may be due to MK-801 working as both an NMDAr antagonist and DA agonist (Hiramatsu, Cho \& Nabeshima, 1989; Mathe et al., 1999). A similar NMDAr antagonist and DAr agonist ketamine has been shown to increase LTP in the NAc and hippocampus through D1 receptor activation (Belujon \& Grace, 2014). MK-801 has been demonstrated to increase burst firing of dopaminergic VTA neurons (French \& Cici, 1990; Belujon \& Grace, 2014) and increase DA release while decreasing DA 
reuptake in the NAc (Hancock \& Stamford, 1999). During acquisition, VTA neurons initially fire to the presentation of a reward and then fire to the presentation of the conditioned stimulus (Schultz, 1999). It is likely that MK-801 primarily acts in the VTA when injected systemically because similar behavioural effects are seen when it is injected directly into the VTA (Narayanan et al., 1996). Therefore, MK-801 may facilitate the formation of stimulus-response associations by increasing NAc DA via the VTA. Similarily, MK-801 $(0.1 \mathrm{mg} / \mathrm{kg})$ may increase food craving, demonstrated by increased place preference conditioning (PPC) (Yonghui et al., 2006) Furthermore, NMDAr antagonism has been demonstrated to increase extracellular glutamate (Moghaddam et al., 1997; Sebban et al., 2002; Lorrain et al., 2003). Glutamate, unlike DA, can activate or inactive neurons within milliseconds (Lapish, et al., 2006) and may further increase the stimulus-response associations by enhancing dopaminergic signals from the VTA.

In the present study the late MK-801 group $(0.05 \mathrm{mg} / \mathrm{kg})$ had elevated locomotor activity compared to saline. This is inconsistent with previous research in our laboratory and others that found that a low dose $(0.05 \mathrm{mg} / \mathrm{kg})$ did not affect locomotor activity (Tuplin, Stocco \& Holahan, 2015; Carey, Dai \& Gui, 1998; Liljequist, 1991; Nakagawa \& Iwasaki, 1996; Gilmour et al., 2009; Liu et al., 2017). However, moderate (0.1mg/kg) (Tuplin, Stocco \& Holahan, 2015; Ouagazzal et al., 1994; Narayanan et al., 1996; Kesby et al., 2012; Zavitsanou et al., 2014; Hasegawa et al., 2016; Druhan, Rajabi \& Stewart 1996; Rung et al., 2005) and high doses $(0.2 \mathrm{mg} / \mathrm{kg}-0.5 \mathrm{mg} / \mathrm{kg})$ increased locomotor activity (Tricklebank et al., 1989; Bygrave et al., 2016; Druhan, Rajabi \& Stewart 1996; Hiramatsu, Cho \& Nabeshima, 1989; Gilmour et al., 2009; Liu et al., 2017; Rung et al., 2005). Increased locomotion is likely due to an increase in DA in the dorsal and ventral striatum (Ouagazzal et al., 1994; Narayanan et al., 1996) as well as the VTA (Narayanan et al., 1996). Similarly, DA antagonists have been demonstrated to reverse 
MK-801 induced locomotor activity (Hoffman, 1992; Lapin \& Rogawski, 1994; Mele et al., 1996). The rats used in the current study were adolescence therefore the increased locomotion compared to past studies seen after the low dose $(0.05 \mathrm{mg} / \mathrm{kg})$ could be due to lower body weight.

\section{Conclusion \& Future Directions}

To conclude, early treatment with Flupenthixol enhanced operant conditioning possibly through sensitized DAr in the NAc, demonstrated by increased cellular activity after apomorphine in comparison to the saline control. No morphological changes were found between treatment groups, indicating that behavioural differences seen were not do to structural changes in the NAc. Flupenthixol given before operant acquisition decreased operant conditioning and locomotor activity, likely through DAr blockade (Floresco., Tse \& GhodsSharifi, 2008).

Early treatment with MK-801 did not produce a learning deficit and did not produce morphological changes in the NAc. However, basal levels of c-Fos were higher in the early MK801 group, possibly due to NMDAr subunit changes and thus an increased likelihood for LTP to occur (Yashiro \& Philpot, 2008). Future studies would benefit from using Western blot analyses to measure protein levels of NR2B and NR2A subunits and compare the early-MK-801 treatment with saline controls during adolescence. MK-801 administrated before operant condition enhanced acquisition and locomotor activity. MK-801 is both an NMDAr antagonist and DA agonist (Hiramatsu, Cho \& Nabeshima, 1989) and likely helps form stimulus-response associations through VTA neurons releasing DA into the NAc (Schultz, 1999; French \& Cici, 1990).

There are some inconsistencies in the literature regarding both flupenthixol and MK-801 in operant conditioning and development. Future studies may benefit from having a dose- 
response curve to better elucidate the role of DAr and NMDAr in the developmental and immediate effects of both flupenthixol and MK-801 on associative learning. However, the current study discovered important information, as stated above. Taken together, these results demonstrate the importance of increased DA in operant acquisition and locomotion, either through the immediate effects of a drug or through DAr sensitization during development. 


\section{References}

Abraham, W. C., \& Bear, M. F. (1996). Metaplasticity: the plasticity of synaptic plasticity. Trends in Neurosciences, 19(4), 126-130.

Aristotle. (2011). Nicomachean Ethics. (R. C. Bartlett, \& S. D. Collins, Ed.) Chicago - London: The University of Chicago Press.

Balleine, B., \& Killcross, S. (1994). Effects of ibotenic acid lesions of the nucleus accumbens on instrumental action. Behavioural Brain Research, 65(2), 181-193.

Beattie, E. C., Carroll, R. C., Yu, X., Morishita, W., Yasuda, H., von Zastrow, M., \& Malenka, R. C. (2000). Regulation of AMPA receptor endocytosis by a signaling mechanism shared with LTD. Nature Neuroscience, 3(12), 1291-1300.

Barria, A., \& Malinow, R. (2005). NMDA receptor subunit composition controls synaptic plasticity by regulating binding to CaMKII. Neuron, 48(2), 289-301.

Bellone, C., \& Lüscher, C. (2005). mGluRs induce a long-term depression in the ventral tegmental area that involves a switch of the subunit composition of AMPA receptors. The European Journal of Neuroscience, 21(5), 1280-1288.

Bellone, C., \& Lüscher, C. (2012). Drug-evoked plasticity: do addictive drugs reopen a critical period of postnatal synaptic development? Frontiers in Molecular Neuroscience, 5, 75.

Belujon, P., \& Grace, A. A. (2014). Restoring mood balance in depression: ketamine reverses deficit in dopamine-dependent synaptic plasticity. Biological Psychiatry, 76(12), 927936.

Ben-Ari, Y., Khazipov, R., Leinekugel, X., Caillard, O., \& Gaiarsa, J.-L. (1997). GABAA, NMDA and AMPA receptors: a developmentally regulatedmenage a trois'. Trends in Neurosciences, 20(11), 523-529.

Beninger, R. J. (1983). The role of dopamine in locomotor activity and learning. Brain Research, 287(2), 173-196.

Bonci, A., \& Malenka, R. C. (1999). Properties and plasticity of excitatory synapses on dopaminergic and GABAergic cells in the ventral tegmental area. The Journal of Neuroscience: The Official Journal of the Society for Neuroscience, 19(10), 3723-3730.

Borchgrave, R., Rawlins, J. N. P., Dickinson, A., \& Balleine, B. W. (2002). Effects of cytotoxic nucleus accumbens lesions on instrumental conditioning in rats. Experimental Brain Research. Experimentelle Hirnforschung. Experimentation Cerebrale, 144(1), 50-68. 
Braun, A. R., Laruelle, M., \& Mouradian, M. M. (1997). Interactions between D1 and D2 dopamine receptor family agonists and antagonists: the effects of chronic exposure on behavior and receptor binding in rats and their clinical implications. Journal of Neural Transmission, 104(4-5), 341-362.

Brog, J. S., Salyapongse, A., Deutch, A. Y., \& Zahm, D. S. (1993). The patterns of afferent innervation of the core and shell in the "accumbens" part of the rat ventral striatum: immunohistochemical detection of retrogradely transported fluoro-gold. The Journal of Comparative Neurology, 338(2), 255-278.

Bygrave, A. M., Masiulis, S., Nicholson, E., Berkemann, M., Barkus, C., Sprengel, R., Kätzel, D. (2016). Knockout of NMDA-receptors from parvalbumin interneurons sensitizes to schizophrenia-related deficits induced by MK-801. Translational Psychiatry, $6, \mathrm{e} 778$.

Cajal S. [1906] 1967. The structure and connexions of neurons. In: Nobel Lectures: Physiology or Medicine, 1901-1921, pp. 220-253. Amsterdam: Elsevier.

Cajal, S. R. (1888). Estructura de los centros nerviosos de las aves. Rev Trim Histol Norm Patol, $1,1-10$.

Calabresi, P., Pisani, A., Mercuri, N. B., \& Bernardi, G. (1992). Long-term Potentiation in the Striatum is Unmasked by Removing the Voltage-dependent Magnesium Block of NMDA Receptor Channels. The European Journal of Neuroscience, 4(10), 929-935.

Calabresi, P., Gubellini, P., Centonze, D., Picconi, B., Bernardi, G., Chergui, K., Greengard, P. (2000). Dopamine and cAMP-regulated phosphoprotein $32 \mathrm{kDa}$ controls both striatal long-term depression and long-term potentiation, opposing forms of synaptic plasticity. The Journal of Neuroscience: The Official Journal of the Society for Neuroscience, 20(22), 8443-8451.

Carelli, R. M., \& Ijames, S. G. (2000). Nucleus accumbens cell firing during maintenance, extinction, and reinstatement of cocaine self-administration behavior in rats. Brain Research, 866(1-2), 44-54.

Carey, R. J., Dai, H., \& Gui, J. (1998). Effects of dizocilpine (MK-801) on motor activity and memory. Psychopharmacology, 137(3), 241-246.

Castro, R., Abreu, P., Calzadilla, C. H., \& Rodriguez, M. (1985). Increased or decreased locomotor response in rats following repeated administration of apomorphine depends on dosage interval. Psychopharmacology, 85(3), 333-339.

Cenci, M. A., Campbell, K., Wictorin, K., \& Björklund, A. (1992). Striatal c-Fos Induction by Cocaine or Apomorphine Occurs Preferentially in Output Neurons Projecting to the Substantia Nigra in the Rat. The European Journal of Neuroscience, 4(4), 376-380. 
Cerovic, M., d'Isa, R., Tonini, R., \& Brambilla, R. (2013). Molecular and cellular mechanisms of dopamine-mediated behavioral plasticity in the striatum. Neurobiology of Learning and Memory, 105, 63-80.

Cheng, J. J., de Bruin, J. P. C., \& Feenstra, M. G. P. (2003). Dopamine efflux in nucleus accumbens shell and core in response to appetitive classical conditioning. The European Journal of Neuroscience, 18(5), 1306-1314.

Chen, B. T., Hopf, F. W., \& Bonci, A. (2010). Synaptic plasticity in the mesolimbic system: therapeutic implications for substance abuse. Annals of the New York Academy of Sciences, 1187, 129-139.

Choi, S., \& Lovinger, D. M. (1997). Decreased probability of neurotransmitter release underlies striatal long-term depression and postnatal development of corticostriatal synapses. Proceedings of the National Academy of Sciences of the United States of America, 94(6), 2665-2670.

Churchill, L., Cross, R. S., Pazdernik, T. L., Nelson, S. R., Zahm, D. S., Heimer, L., \& Kalivas, P. W. (1992). Patterns of glucose use after bicuculline-induced convulsions in relationship to gamma-aminobutyric acid and mu-opioid receptors in the ventral pallidum--functional markers for the ventral pallidum. Brain Research, 581(1), 39-45.

Churchill, L., \& Kalivas, P. W. (1994). A topographically organized gamma-aminobutyric acid projection from the ventral pallidum to the nucleus accumbens in the rat. The Journal of Comparative Neurology, 345(4), 579-595.

Cimino, G. (1999). Reticular theory versus neuron theory in the work of Camillo Golgi. Physis; Rivista Internazionale Di Storia Della Scienza, 36(2), 431-472.

Clissold, D. B., Ferkany, J. W., \& Pontecorvo, M. J. (1991). Competitive and noncompetitive N-methyl-D-aspartate (NMDA) antagonists, haloperidol, and scopolamine impair performance in a nonspatial operant discrimination task. Psychobiology , 19(4), 332-338.

Cole, A. J., Bhat, R. V., Patt, C., Worley, P. F., \& Baraban, J. M. (1992). D1 dopamine receptor activation of multiple transcription factor genes in rat striatum. Journal of Neurochemistry, 58(4), 1420-1426.

Collingridge, G. L., Kehl - The Journal of ..., S. J., \& 1983. (1983). Excitatory amino acids in synaptic transmission in the Schaffer collateral-commissural pathway of the rat hippocampus. Wiley Online Library.

Corbit, L. H., Muir, J. L., \& Balleine, B. W. (2001). The role of the nucleus accumbens in instrumental conditioning: Evidence of a functional dissociation between accumbens core and shell. The Journal of Neuroscience: The Official Journal of the Society for 
Neuroscience, 21(9), 3251-3260.

Creese, I., Sibley, D. R., Hamblin, M. W., \& Leff, S. E. (1983). The classification of dopamine receptors: relationship to radioligand binding. Annual Review of Neuroscience, 6, 43-71.

Cull-Candy, S., Brickley, S., \& Farrant, M. (2001). NMDA receptor subunits: diversity, development and disease. Current Opinion in Neurobiology, 11(3), 327-335.

Cull-Candy, S. G., \& Leszkiewicz, D. N. (2004). Role of distinct NMDA receptor subtypes at central synapses. Science's STKE: Signal Transduction Knowledge Environment, 2004(255), re16.

Danna, C. L., \& Elmer, G. I. (2010). Disruption of conditioned reward association by typical and atypical antipsychotics. Pharmacology, Biochemistry, and Behavior, 96(1), 40-47.

Davies, J., Francis, A. A., Jones, A. W., \& Watkins, J. C. (1981). 2-Amino-5-phosphonovalerate (2APV), a potent and selective antagonist of amino acid-induced and synaptic excitation. Neuroscience Letters, 21(1), 77-81.

Day, J. J., Roitman, M. F., Wightman, R. M., \& Carelli, R. M. (2007). Associative learning mediates dynamic shifts in dopamine signaling in the nucleus accumbens. Nature Neuroscience, 10(8), 1020-1028.

Denk, F., Walton, M. E., Jennings, K. A., Sharp, T., Rushworth, M. F. S., \& Bannerman, D. M. (2005). Differential involvement of serotonin and dopamine systems in cost-benefit decisions about delay or effort. Psychopharmacology, 179(3), 587-596.

Descartes R. [1649] 1984. The Philosophical Writings of Descartes. Cambridge: Cambridge Univ. Press.

Deutch, A. Y., \& Duman, R. S. (1996). The effects of antipsychotic drugs on Fos protein expression in the prefrontal cortex: cellular localization and pharmacological characterization. Neuroscience, 70(2), 377-389.

Di Filippo, M., Picconi, B., Tantucci, M., Ghiglieri, V., Bagetta, V., Sgobio, C., Calabresi, P. (2009). Short-term and long-term plasticity at corticostriatal synapses: implications for learning and memory. Behavioural Brain Research, 199(1), 108-118.

Dickinson, A., Smith, J., \& Mirenowicz, J. (2000). Dissociation of Pavlovian and instrumental incentive learning under dopamine antagonists. Behavioral Neuroscience, 114(3), $468-483$.

Dingledine, R., Borges, K., Bowie, D., \& Traynelis, S. F. (1999). The glutamate receptor ion channels. Pharmacological Reviews, 51(1), 7-61. 
Dobi, A., Margolis, E. B., Wang, H.-L., Harvey, B. K., \& Morales, M. (2010). Glutamatergic and nonglutamatergic neurons of the ventral tegmental area establish local synaptic contacts with dopaminergic and nondopaminergic neurons. The Journal of Neuroscience: The Official Journal of the Society for Neuroscience, 30(1), 218-229.

Donahoe, J. W. \& Palmer, D. C. (1994) Learning and complex behavior. Allyn and Bacon

Donahoe, J. W., Palmer, D. C. \& Burgos, J. E. (1997) The S-R issue: Its status in behavior analysis and in Donahoe and Palmer's Learning and complex behavior. Journal of the Experimental Analysis of Behavior 67:193-211

Doremus-Fitzwater, T. L., Varlinskaya, E. I., \& Spear, L. P. (2010). Motivational systems in adolescence: possible implications for age differences in substance abuse and other risktaking behaviors. Brain and Cognition, 72(1), 114-123.

Doremus-Fitzwater, T. L., \& Spear, L. P. (2016). Reward-centricity and attenuated aversions: An adolescent phenotype emerging from studies in laboratory animals. Neuroscience and Biobehavioral Reviews, 70, 121-134.

Douglas, R. J. (1967). The hippocampus and behavior. Psychological Bulletin, 67(6), 416-422.

Dragunow, M., \& Faull, R. L. (1990). MK-801 induces c-fos protein in thalamic and neocortical neurons of rat brain. Neuroscience Letters, 111(1-2), 39-45.

Druhan, J. P., Rajabi, H., \& Stewart, J. (1996). MK-801 increases locomotor activity without elevating extracellular dopamine levels in the nucleus accumbens. Synapse, 24(2), 135-146.

Duncan, G. E., Moy, S. S., Knapp, D. J., Mueller, R. A., \& Breese, G. R. (1998). Metabolic mapping of the rat brain after subanesthetic doses of ketamine: potential relevance to schizophrenia. Brain Research, 787(2), 181-190.

Durand, G. M., Kovalchuk, Y., \& Konnerth, A. (1996). Long-term potentiation and functional synapse induction in developing hippocampus. Nature, 381(6577), 71-75.

Filipkowski, R. K., Rydz, M., \& Kaczmarek, L. (2001). Expression of c-Fos, Fos B, Jun B, and Zif268 transcription factor proteins in rat barrel cortex following apomorphine-evoked whisking behavior. Neuroscience, 106(4), 679-688.

Floresco, S. B., Tse, M. T. L., \& Ghods-Sharifi, S. (2008). Dopaminergic and glutamatergic regulation of effort- and delay-based decision making. Neuropsychopharmacology:

Official Publication of the American College of Neuropsychopharmacology, 33(8), 1966-1979. 
Floresco, S. B. (2015). The nucleus accumbens: an interface between cognition, emotion, and action. Annual Review of Psychology, 66, 25-52.

Fredriksson, A., \& Archer, T. (2000). Effects of clonidine and alpha-adrenoceptor antagonists on motor activity in DSP4-treated mice II: interactions with apomorphine. Neurotoxicity Research, 1(4), 249-259.

French, E. D., \& Ceci, A. (1990). Non-competitive N-methyl-D-aspartate antagonists are potent activators of ventral tegmental A10 dopamine neurons. Neuroscience Letters, $119(2), 159-162$.

Friemel, C. M., Spanagel, R., \& Schneider, M. (2010). Reward sensitivity for a palatable food reward peaks during pubertal developmental in rats. Frontiers in Behavioral Neuroscience, 4. https://doi.org/10.3389/fnbeh.2010.00039

Gass, P., Herdegen, T., Bravo, R., \& Kiessling, M. (1993). Induction and suppression of immediate early genes in specific rat brain regions by the non-competitive N-methyl-Daspartate receptor antagonist MK-801. Neuroscience, 53(3), 749-758.

Gerfen, C. R., Herkenham, M., \& Thibault, J. (1987). The neostriatal mosaic: II. Patch- and matrix-directed mesostriatal dopaminergic and non-dopaminergic systems. The Journal of Neuroscience: The Official Journal of the Society for Neuroscience, 7(12), 3915-3934.

Gluck, M. A., Mercado, E., \& Myers, C. E. (2016). Learning and Memory: From Brain to Behavior. Worth Publishers.

Gilmour, G., Pioli, E. Y., Dix, S. L., Smith, J. W., Conway, M. W., Jones, W. T., Tricklebank, M. D. (2009). Diverse and often opposite behavioural effects of NMDA receptor antagonists in rats: implications for "NMDA antagonist modelling" of schizophrenia. Psychopharmacology, 205(2), 203-216.

Gipson, C. D., Kupchik, Y. M., \& Kalivas, P. W. (2014). Rapid, transient synaptic plasticity in addiction. Neuropharmacology, 76 Pt B, 276-286.

Girault, J.-A., Valjent, E., Caboche, J., \& Hervé, D. (2007). ERK2: a logical AND gate critical for drug-induced plasticity? Current Opinion in Pharmacology, 7(1), 77-85.

Golgi C. [1906] 1967. The neuron doctrine: theory and facts. In: Nobel Lectures: Physiology or Medicine, 1901-1921, pp. 189-217. Amsterdam: Elsevier.

Gonon, F. (1997). Prolonged and extrasynaptic excitatory action of dopamine mediated by D1 receptors in the rat striatum in vivo. The Journal of Neuroscience: The Official Journal of the Society for Neuroscience, 17(15), 5972-5978. 
Goodman, C. S., \& Shatz, C. J. (1993). Developmental mechanisms that generate precise patterns of neuronal connectivity. Cell, 72 Suppl, 77-98.

Gorter, J. A., \& de Bruin, J. P. (1992). Chronic neonatal MK-801 treatment results in an impairment of spatial learning in the adult rat. Brain Research, 580(1-2), 12-17.

Greengard, P. (2001). The neurobiology of slow synaptic transmission. Science, 294(5544), $1024-1030$.

Hancock, P. J., \& Stamford, J. A. (1999). Stereospecific effects of ketamine on dopamine efflux and uptake in the rat nucleus accumbens. British Journal of Anaesthesia, 82(4), 603-608.

Hebb, D. O. (1949). The organization of behavior: A neuropsychological theory. John Wiley \& Sons.

Heimer, L., Zahm, D. S., Churchill, L., Kalivas, P. W., \& Wohltmann, C. (1991). Specificity in the projection patterns of accumbal core and shell in the rat. Neuroscience, 41(1), 89125.

Hess, E. J., Norman, A. B., \& Creese, I. (1988). Chronic treatment with dopamine receptor antagonists: behavioral and pharmacologic effects on D1 and D2 dopamine receptors. The Journal of Neuroscience: The Official Journal of the Society for Neuroscience, 8(7), 2361-2370.

Hasegawa, Y., Inoue, T., Kawaminami, S., \& Fujita, M. (2016). Effects of scallop shell extract on scopolamine-induced memory impairment and MK801-induced locomotor activity. Asian Pacific Journal of Tropical Medicine, 9(7), 662-667.

Hernandez, P. J., Sadeghian, K., \& Kelley, A. E. (2002). Early consolidation of instrumental learning requires protein synthesis in the nucleus accumbens. Nature Neuroscience, $5(12), 1327-1331$.

Hiramatsu, M., Cho, A. K., \& Nabeshima, T. (1989). Comparison of the behavioral and biochemical effects of the NMDA receptor antagonists, MK-801 and phencyclidine. European Journal of Pharmacology, 166(3), 359-366.

Hoffman, D. C. (1992). Typical and atypical neuroleptics antagonize MK-801-induced locomotion and stereotypy in rats. Journal of Neural Transmission. General Section, 89(1-2), 1-10.

Horvitz, J. C. (2009). Stimulus-response and response-outcome learning mechanisms in the striatum. Behavioural Brain Research, 199(1), 129-140. 
Hume D. (1748) An enquiry concerning human understanding. Buffalo: Prometheus Press, 1988

Inta, I., Domonkos, E., Pfeiffer, N., Sprengel, R., Bettendorf, M., Lang, U. E. Gass, P. (2017). Puberty marks major changes in the hippocampal and cortical c-Fos activation pattern induced by NMDA receptor antagonists. Neuropharmacology, 112(Pt A), 181-187.

Inada, K., Farrington, J. S., Moy, S. S., Koller, B. H., \& Duncan, G. E. (2007). Assessment of NMDA receptor activation in vivo by Fos induction after challenge with the direct NMDA agonist (tetrazol-5-yl)glycine: effects of clozapine and haloperidol. Journal of Neural Transmission , 114(7), 899-908.

Jay, T. M., \& Witter, M. P. (1991). Distribution of hippocampal CA1 and subicular efferents in the prefrontal cortex of the rat studied by means of anterograde transport of Phaseolus vulgaris-leucoagglutinin. The Journal of Comparative Neurology, 313(4), 574-586.

Ji, X., \& Martin, G. E. (2012). New rules governing synaptic plasticity in core nucleus accumbens medium spiny neurons. The European Journal of Neuroscience, 36(12), 3615-3627

Johnson, D. W., \& Glick, S. D. (1993). Dopamine release and metabolism in nucleus accumbens and striatum of morphine-tolerant and nontolerant rats. Pharmacology, Biochemistry, and Behavior, 46(2), 341-347.

Kalivas, P. W., \& Duffy, P. (1990). Effect of acute and daily cocaine treatment on extracellular dopamine in the nucleus accumbens. Synapse , 5(1), 48-58.

Kalsbeek, A., Voorn, P., Buijs, R. M., Pool, C. W., \& Uylings, H. B. (1988). Development of the dopaminergic innervation in the prefrontal cortex of the rat. The Journal of Comparative Neurology, 269(1), 58-72.

Kania, B. F., Wrońska, D., \& Zięba, D. (2017). Introduction to Neural Plasticity Mechanism. Journal of Behavioral and Brain Science, 07(02), 41.

Kawaguchi, Y., Wilson, C. J., Augood, S. J., \& Emson, P. C. (1995). Striatal interneurones: chemical, physiological and morphological characterization. Trends in Neurosciences, 18(12), 527-535.

Kawano, M., Kawasaki, A., Sakata-Haga, H., Fukui, Y., Kawano, H., Nogami, H., \& Hisano, S. (2006). Particular subpopulations of midbrain and hypothalamic dopamine neurons express vesicular glutamate transporter 2 in the rat brain. The Journal of Comparative Neurology, 498(5), 581-592.

Keilhoff, G., Becker, A., Grecksch, G., Wolf, G., \& Bernstein, H.-G. (2004). Repeated application of ketamine to rats induces changes in the hippocampal expression of parvalbumin, neuronal nitric oxide synthase and cFOS similar to those found in human schizophrenia. Neuroscience, 126(3), 591-598. 
Kelley, A. E., Domesick, V. B., \& Nauta, W. J. H. (1982). The amygdalostriatal projection in the rat - an anatomical study by anterograde and retrograde tracing methods. Neuroscience, $7(3), 615-630$.

Kelley, A. E., Smith-Roe, S. L., \& Holahan, M. R. (1997). Response-reinforcement learning is dependent on N-methyl-D-aspartate receptor activation in the nucleus accumbens core. Proceedings of the National Academy of Sciences of the United States of America, 94(22), 12174-12179.

Kelley, A. E. (2004). Memory and addiction: shared neural circuitry and molecular mechanisms. Neuron, 44(1), 161-179.

Kerr, J. N., \& Wickens, J. R. (2001). Dopamine D-1/D-5 receptor activation is required for longterm potentiation in the rat neostriatum in vitro. Journal of Neurophysiology, 85(1), 117124.

Kesby, J. P., O’Loan, J. C., Alexander, S., Deng, C., Huang, X.-F., McGrath, J. J., Burne, T. H. J. (2012). Developmental vitamin D deficiency alters MK-801-induced behaviours in adult offspring. Psychopharmacology, 220(3), 455-463.

Kirkwood, A., Rioult, M. C., \& Bear, M. F. (1996). Experience-dependent modification of synaptic plasticity in visual cortex. Nature, 381(6582), 526-528.

Kombian, S. B., \& Malenka, R. C. (1994). Simultaneous LTP of non-NMDA- and LTD of NMDA-receptor-mediated responses in the nucleus accumbens. Nature, 368(6468), 242246.

Kreitzer, A. C. (2009). Physiology and pharmacology of striatal neurons. Annual Review of Neuroscience, 32, 127-147.

Kullmann, D. M. (1994). Amplitude fluctuations of. Neuron, 12(5), 1111-1120.

Lapin, I. P., \& Rogawski, M. A. (1995). Effects of D1 and D2 dopamine receptor antagonists and catecholamine depleting agents on the locomotor stimulation induced by dizocilpine in mice. Behavioural Brain Research, 70(2), 145-151.

Lapish, C. C., Seamans, J. K., \& Chandler, L. J. (2006). Glutamate-dopamine cotransmission and reward processing in addiction. Alcoholism, Clinical and Experimental Research, 30(9), $1451-1465$.

Lerea, L. S., Butler, L. S., \& McNamara, J. O. (1992). NMDA and non-NMDA receptormediated increase of c-fos mRNA in dentate gyrus neurons involves calcium influx via different routes. The Journal of Neuroscience: The Official Journal of the Society for 
Neuroscience, 12(8), 2973-2981.

Liljequist, S. (1991). Genetic differences in the effects of competitive and non-competitive NMDA receptor antagonists on locomotor activity in mice. Psychopharmacology, 104(1), $17-21$.

Lim, A. L., Taylor, D. A., \& Malone, D. T. (2012). A two-hit model: behavioural investigation of the effect of combined neonatal MK-801 administration and isolation rearing in the rat. Journal of Psychopharmacology, 26(9), 1252-1264.

Lisman - Proceedings of the National Academy of, J., \& 1989. (1989). A mechanism for the Hebb and the anti-Hebb processes underlying learning and memory. National Acad Sciences.

Liu, W., Wang, D., Hong, W., Yu, Y., Tang, J., Wang, J., Chen, X. (2017). Psychotomimetic effects of different doses of MK-801 and the underlying mechanisms in a selective memory impairment model. Behavioural Brain Research, 320, 517-525.

Locke J. 1690. An Essay Concerning Human Understanding. In Four Books. London: printed for T. Bassett.

Lømo, T. 1966 Frequency potentiation of excitatory synaptic activity in the dentate area of the hippocampal formation. Acta Physiol. Scand. 68(Suppl. 277), 128.

Lomo, T. \& Bliss, T. V., \& (1973). Long-lasting potentiation of synaptic transmission in the dentate area of the anaesthetized rabbit following stimulation of the perforant path. The Journal of Physiology, 232(2), 331-356.

Lorrain, D. S., Baccei, C. S., Bristow, L. J., Anderson, J. J., \& Varney, M. A. (2003). Effects of ketamine and $\mathrm{N}$-methyl-D-aspartate on glutamate and dopamine release in the rat prefrontal cortex: modulation by a group II selective metabotropic glutamate receptor agonist LY379268. Neuroscience, 117(3), 697-706.

Lynch, G., Larson, J., Kelso, S., Barrionuevo, G., \& Schottler, F. (1983). Intracellular injections of EGTA block induction of hippocampal long-term potentiation. Nature, 305(5936), 719-721.

Malenka, R. C., Kauer, J. A., Zucker, R. S., \& Nicoll, R. A. (1988). Postsynaptic calcium is sufficient for potentiation of hippocampal synaptic transmission. Science, 242(4875), 8184.

Mameli, M., Bellone, C., Brown, M. T. C., \& Lüscher, C. (2011). Cocaine inverts rules for synaptic plasticity of glutamate transmission in the ventral tegmental area. Nature Neuroscience, 14(4), 414-416.

Mathé, J. M., Nomikos, G. G., Blakeman, K. H., \& Svensson, T. H. (1999). Differential actions of dizocilpine (MK-801) on the mesolimbic and mesocortical dopamine systems: role of 
neuronal activity. Neuropharmacology, 38(1), 121-128.

Margrie, T. W., Brecht, M., \& Sakmann, B. (2002). In vivo, low-resistance, whole-cell recordings from neurons in the anaesthetized and awake mammalian brain. Pflugers Archiv: European Journal of Physiology, 444(4), 491-498.

Mele, A., Castellano, C., Felici, A., Cabib, S., Caccia, S., \& Oliverio, A. (1996). Dopamine$\mathrm{N}$-methyl-D-aspartate interactions in the modulation of locomotor activity and memory consolidation in mice. European Journal of Pharmacology, 308(1), 1-12.

Meredith, G. E. (1999). The synaptic framework for chemical signaling in nucleus accumbens. Annals of the New York Academy of Sciences, 877, 140-156.

Meredith, G. E., Blank, B., \& Groenewegen, H. J. (1989). The distribution and compartmental organization of the cholinergic neurons in nucleus accumbens of the rat. Neuroscience, 31(2), 327-345.

Meredith, G. E., Agolia, R., Arts, M. P., Groenewegen, H. J., \& Zahm, D. S. (1992). Morphological differences between projection neurons of the core and shell in the nucleus accumbens of the rat. Neuroscience, 50(1), 149-162.

Meredith, G. E., Pennartz, C. M., \& Groenewegen, H. J. (1993). The cellular framework for chemical signalling in the nucleus accumbens. Progress in Brain Research, 99, 3-24.

Miles, R., Poncer, J.-C., Fricker, D., \& Leinekugel, X. (2005). The birth (and adolescence) of LTP. The Journal of Physiology, 568(Pt 1), 1-2.

Mogenson, G. J., Jones, D. L., \& Yim, C. Y. (1980). From motivation to action: functional interface between the limbic system and the motor system. Progress in Neurobiology, 14(2-3), 69-97.

Moghaddam, B., Adams, B., Verma, A., \& Daly, D. (1997). Activation of glutamatergic neurotransmission by ketamine: a novel step in the pathway from NMDA receptor blockade to dopaminergic and cognitive disruptions associated with the prefrontal cortex. The Journal of Neuroscience: The Official Journal of the Society for Neuroscience, 17(8), 2921-2927.

Monyer, H., Burnashev, N., Laurie, D. J., Sakmann, B., \& Seeburg, P. H. (1994). Developmental and regional expression in the rat brain and functional properties of four NMDA receptors. Neuron, 12(3), 529-540.

Moore, R. Y., \& Bloom, F. E. (1978). Central catecholamine neuron systems: anatomy and physiology of the dopamine systems. Annual Review of Neuroscience, 1, 129-169.

Nabavi, S., Fox, R., Proulx, C. D., Lin, J. Y., Tsien, R. Y., \& Malinow, R. (2014). Engineering a memory with LTD and LTP. Nature, 511(7509), 348-352. 
Nair-Roberts, R. G., Chatelain-Badie, S. D., Benson, E., White-Cooper, H., Bolam, J. P., \& Ungless, M. A. (2008). Stereological estimates of dopaminergic, GABAergic and glutamatergic neurons in the ventral tegmental area, substantia nigra and retrorubral field in the rat. Neuroscience, 152(4), 1024-1031.

Nakano, T., Doi, T., Yoshimoto, J., \& Doya, K. (2010). A kinetic model of dopamine- and calcium-dependent striatal synaptic plasticity. PLoS Computational Biology, 6(2), e1000670.

Nakagawa, Y., \& Iwasaki, T. (1996). Ethanol-induced state-dependent learning is mediated by 5hydroxytryptamine 3 receptors but not byN-methyl-d-aspartate receptor complex. Brain Research, 706(2), 227-232.

Narayanan, S., Willins, D., Dalia, A., Wallace, L., \& Uretsky, N. (1996). Role of dopaminergic mechanisms in the stimulatory effects of MK-801 injected into the ventral tegmental area and the nucleus accumbens. Pharmacology, Biochemistry, and Behavior, 54(3), 565-573.

Nase, G., Weishaupt, J., Stern, P., Singer, W., \& Monyer, H. (1999). Genetic and epigenetic regulation of NMDA receptor expression in the rat visual cortex. The European Journal of Neuroscience, 11(12), 4320-4326.

Németh, H., Varga, H., Farkas, T., Kis, Z., Vécsei, L., Horváth, S., Toldi, J. (2002). Long-term effects of neonatal MK-801 treatment on spatial learning and cortical plasticity in adult rats. Psychopharmacology, 160(1), 1-8.

Nicola, S. M. (2010). The flexible approach hypothesis: unification of effort and cue-responding hypotheses for the role of nucleus accumbens dopamine in the activation of rewardseeking behavior. The Journal of Neuroscience: The Official Journal of the Society for Neuroscience, 30(49), 16585-16600.

Nielsen, I. M., Pedersen, V., Nymark, M., Franck, K. F., Boeck, V., Fjalland, B., \& Christensen, A. V. (1973). The comparative pharmacology of flupenthixol and some reference neuroleptics. Acta Pharmacologica et Toxicologica, 33(5), 353-362.

Nirenberg, M. J., Vaughan, R. A., Uhl, G. R., Kuhar, M. J., \& Pickel, V. M. (1996). The dopamine transporter is localized to dendritic and axonal plasma membranes of nigrostriatal dopaminergic neurons. The Journal of Neuroscience: The Official Journal of the Society for Neuroscience, 16(2), 436-447.

Nordstrom, A. L., Farde, L., Nyberg, S., \& Karlsson, P. (1995). D1, D2, and 5-HT2 receptor occupancy in relation to clozapine serum concentration: a PET study of schizophrenic patients. American Journal of.

Novak, G., Fan, T., O’Dowd, B. F., \& George, S. R. (2013). Striatal development involves a 
switch in gene expression networks, followed by a myelination event: implications for neuropsychiatric disease. Synapse, 67(4), 179-188.

Ouagazzal, A., Nieoullon, A., \& Amalric, M. (1994). Locomotor activation induced by MK-801 in the rat: postsynaptic interactions with dopamine receptors in the ventral striatum. European Journal of Pharmacology, 251(2-3), 229-236.

Partridge, J. G., Tang, K. C., \& Lovinger, D. M. (2000). Regional and postnatal heterogeneity of activity-dependent long-term changes in synaptic efficacy in the dorsal striatum. Journal of Neurophysiology, 84(3), 1422-1429.

Patel, S., Roberts, J., Moorman, J., \& Reavill, C. (1995). Localization of serotonin-4 receptors in the striatonigral pathway in rat brain. Neuroscience, 69(4), 1159-1167.

Pavlov, I. P. (1927). Conditioned Re exes: An Investigation of the Physiological Activity of the Cerebral Cortex. (G.V, Trans). London: Oxford Univ. Press.

Pennypacker, K. R., Zhang, W. Q., Ye, H., \& Hong, J. S. (1992). Apomorphine induction of AP-1 DNA binding in the rat striatum after dopamine depletion. Brain Research. Molecular Brain Research, 15(1-2), 151-155.

Petri, H. L., \& Mishkin, M. (1994). Behaviorism, Cognitivism and the Neuropsychology of Memory. American Scientist, 82(1), 30-37.

Pijnenburg, A. J. J., \& Rossum, J. M. (1973). Stimulation of locomotor activity following injection of dopamine into the nucleus accumbens. The Journal of Pharmacy and Pharmacology, 25(12), 1003-1005.

Plato. (1984). Dialogues (R.E. Allen, Trans.). New Haven: Yale University Press.

Port, R. L., Murphy, H. A., Magee, R. A., \& Seybold, K. S. (1996). Prior instrumental conditioning improves spatial cognition and attenuates changes in hippocampal function in aged rats. The Journals of Gerontology. Series A, Biological Sciences and Medical Sciences, 51(1), B17-B20.

Powell, E. W., \& Leman, R. B. (1976). Connections of the nucleus accumbens. Brain Research, 105(3), 389-403.

Puig, M. V., Celada, P., Díaz-Mataix, L., \& Artigas, F. (2003). In vivo modulation of the activity of pyramidal neurons in the rat medial prefrontal cortex by 5-HT2A receptors: relationship to thalamocortical afferents. Cerebral Cortex , 13(8), 870-882.

Rapanelli, M., Frick, L. R., Bernardez-Vidal, M., \& Zanutto, B. S. (2013). Different MK-801 administration schedules induce mild to severe learning impairments in an operant conditioning task: role of buspirone and risperidone in ameliorating these cognitive deficits. Behavioural Brain Research, 257, 156-165. 
Rebec, G. V., Bashore, T. R., Zimmerman, K. S., \& Alloway, K. D. (1979). "Classical” and "atypical" antipsychotic drugs: differential antagonism of amphetamine- and apomorphine-induced alterations of spontaneous neuronal activity in the neostriatum and nucleus accumbens. Pharmacology, Biochemistry, and Behavior, 11(5), 529-538.

Reynolds, I. J., Murphy, S. N., \& Miller, R. J. (1987). 3H-labeled MK-801 binding to the excitatory amino acid receptor complex from rat brain is enhanced by glycine. Proceedings of the National Academy of Sciences of the United States of America, 84(21), 7744-7748.

Reynolds, J. N., Hyland, B. I., \& Wickens, J. R. (2001). A cellular mechanism of reward-related learning. Nature, 413(6851), 67-70.

Robbe, D., Bockaert, J., \& Manzoni, O. J. (2002). Metabotropic glutamate receptor 2/3dependent long-term depression in the nucleus accumbens is blocked in morphine withdrawn mice. The European Journal of Neuroscience, 16(11), 2231-2235.

Roberts, E. B., \& Ramoa, A. S. (1999). Enhanced NR2A subunit expression and decreased NMDA receptor decay time at the onset of ocular dominance plasticity in the ferret. Journal of Neurophysiology, 81(5), 2587-2591.

Rogers, A., Schmuck, G., Scholz, G., Griffiths, R., Meredith, C., Schousboe, A., Williams, D. C. (2005). Improvements in an in-vitro assay for excitotoxicity by measurement of early gene (c-fos mRNA) levels. Archives of Toxicology, 79(3), 129-139.

Rujescu, D., Bender, A., Keck, M., Hartmann, A. M., Ohl, F., Raeder, H., Grunze, H. (2006). A pharmacological model for psychosis based on N-methyl-D-aspartate receptor hypofunction: molecular, cellular, functional and behavioral abnormalities. Biological Psychiatry, 59(8), 721-729.

Rung, J. P., Carlsson, A., Rydén Markinhuhta, K., \& Carlsson, M. L. (2005). (+)-MK-801 induced social withdrawal in rats; a model for negative symptoms of schizophrenia. Progress in Neuro-Psychopharmacology \& Biological Psychiatry, 29(5), 827-832.

Saint Marie, R. L., Neary, A. C., Shoemaker, J. M., \& Swerdlow, N. R. (2006). The effects of apomorphine and d-amphetamine on striatal c-Fos expression in Sprague-Dawley and Long Evans rats and their F1 progeny. Brain Research, 1119(1), 203-214.

Salamone, J. D., Johnson, C. J., McCullough, L. D., \& Steinpreis, R. E. (1990). Lateral striatal cholinergic mechanisms involved in oral motor activities in the rat. Psychopharmacology, 102(4), 529-534.

Salamone, J. D., Steinpreis, R. E., McCullough, L. D., Smith, P., Grebel, D., \& Mahan, K. (1991). Haloperidol and nucleus accumbens dopamine depletion suppress lever pressing 
for food but increase free food consumption in a novel food choice procedure. Psychopharmacology, 104(4), 515-521

Salamone, J. D., Arizzi, M. N., Sandoval, M. D., Cervone, K. M., \& Aberman, J. E. (2002). Dopamine antagonists alter response allocation but do not suppress appetite for food in rats: contrast between the effects of SKF 83566, raclopride, and fenfluramine on a concurrent choice task. Psychopharmacology, 160(4), 371-380.

Salgado, S., \& Kaplitt, M. G. (2015). The Nucleus Accumbens: A Comprehensive Review. Stereotactic and Functional Neurosurgery, 93(2), 75-93.

Sandstrom, M. I., Nelson, C. L., \& Bruno, J. P. (2003). Neurochemical correlates of sparing from motor deficits in rats depleted of striatal dopamine as weanlings. Developmental Psychobiology, 43(4), 373-383.

Sanger, D. J., \& Jackson, A. (1989). Effects of phencyclidine and other N-methyl-D-aspartate antagonists on the schedule-controlled behavior of rats. The Journal of Pharmacology and Experimental Therapeutics, 248(3), 1215-1221.

Scofield, M. D., Heinsbroek, J. A., Gipson, C. D., Kupchik, Y. M., Spencer, S., Smith, A. C. W., Kalivas, P. W. (2016). The Nucleus Accumbens: Mechanisms of Addiction across Drug Classes Reflect the Importance of Glutamate Homeostasis. Pharmacological Reviews, 68(3), 816-871.

Schramm, N. L., Egli, R. E., \& Winder, D. G. (2002). LTP in the mouse nucleus accumbens is developmentally regulated. Synapse , 45(4), 213-219.

Schultz, W., Dayan, P., \& Montague, P. R. (1997). A neural substrate of prediction and reward. Science, 275(5306), 1593-1599.

Schultz, W. (1999). The Reward Signal of Midbrain Dopamine Neurons. News in Physiological Sciences: An International Journal of Physiology Produced Jointly by the International Union of Physiological Sciences and the American Physiological Society, 14, 249-255.

Sebban, C., Tesolin-Decros, B., Ciprian-Ollivier, J., Perret, L., \& Spedding, M. (2002). Effects of phencyclidine (PCP) and MK 801 on the EEGq in the prefrontal cortex of conscious rats; antagonism by clozapine, and antagonists of AMPA-, $\alpha 1$-and 5-HT2A-receptors. British Journal of Pharmacology, 135(1), 65-78.

Seeman, P. (1987). Dopamine receptors and the dopamine hypothesis of schizophrenia. Synapse , 1(2), 133-152.

Seeman, P., Schwarz, J., Chen, J.-F., Szechtman, H., Perreault, M., McKnight, G. S.,Sumiyoshi, T. (2006). Psychosis pathways converge via D2high dopamine receptors. Synapse , 60(4), 319-346.

Sesack, S. R., Carr, D. B., Omelchenko, N., \& Pinto, A. (2003). Anatomical Substrates for 
Glutamate-Dopamine Interactions. Annals of the New York Academy of Sciences, 1003(1), 36-52.

Shen, W., Flajolet, M., Greengard, P., \& Surmeier, D. J. (2008). Dichotomous dopaminergic control of striatal synaptic plasticity. Science, 321(5890), 848-851.

Shiflett, M. W., \& Balleine, B. W. (2011). Molecular substrates of action control in corticostriatal circuits. Progress in Neurobiology, 95(1), 1-13.

Smith, D. A., \& Bolam, P J. (1990). The neural network of the basal ganglia as revealed by the study of synaptic connections of identified neurones. Trends in Neurosciences, 13(7), $259-265$.

Smith, J. W., Gastambide, F., Gilmour, G., Dix, S., Foss, J., Lloyd, K., Tricklebank, M. (2011). A comparison of the effects of ketamine and phencyclidine with other antagonists of the NMDA receptor in rodent assays of attention and working memory.

Psychopharmacology, 217(2), 255-269.

Sonnenberg, J. L., Mitchelmore, C., Macgregor-Leon, P. F., Hempstead, J., Morgan, J. I., \& Curran, T. (1989). Glutamate receptor agonists increase the expression of Fos, Fra, and AP-1 DNA binding activity in the mammalian brain. Journal of Neuroscience Research, 24(1), 72-80.

Sotelo, C. (2003). Viewing the brain through the master hand of Ramon y Cajal. Nature Reviews. Neuroscience, 4,71 .

Steiner, H., \& Gerfen, C. R. (1994). Tactile sensory input regulates basal and apomorphineinduced immediate-early gene expression in rat barrel cortex. The Journal of Comparative Neurology, 344(2), 297-304.

Stern, C. E., \& Passingham, R. E. (1996). The nucleus accumbens in monkeys (Macaca fascicularis): II. Emotion and motivation. Behavioural Brain Research, 75(1-2), 179-193.

Stuber, G. D., Klanker, M., de Ridder, B., Bowers, M. S., Joosten, R. N., Feenstra, M. G., \& Bonci, A. (2008). Reward-predictive cues enhance excitatory synaptic strength onto midbrain dopamine neurons. Science, 321(5896), 1690-1692.

Su, Y.-A., Wang, X.-D., Li, J.-T., Guo, C.-M., Feng, Y., Yang, Y., ... Si, T.-M. (2011). Agespecific effects of early MK-801 treatment on working memory in female rats. Neuroreport, 22(8), 402-406.

Surmeier, D. J., Ding, J., Day, M., Wang, Z., \& Shen, W. (2007). D1 and D2 dopamine-receptor modulation of striatal glutamatergic signaling in striatal medium spiny neurons. Trends in Neurosciences, 30(5), 228-235.

Tepper, J. M., Trent, F., \& Nakamura, S. (1990). Postnatal development of the electrical activity of rat nigrostriatal dopaminergic neurons. Brain Research. Developmental Brain 
Research, 54(1), 21-33.

Thorndike, E. L. (1911). Animal intelligence. New York: Macmillan.

Tricklebank, M. D., Singh, L., Oles, R. J., Preston, C., \& Iversen, S. D. (1989). The behavioural effects of MK-801: a comparison with antagonists acting non-competitively and competitively at the NMDA receptor. European Journal of Pharmacology, 167(1), $127-135$.

Tune, L. E., Wong, D. F., Pearlson, G., Strauss, M., Young, T., Shaya, E. K., Sapp, J. (1993). Dopamine D2 receptor density estimates in schizophrenia: a positron emission tomography study with 11C-N-methylspiperone. Psychiatry Research, 49(3), 219-237.

Tuplin, E. W., Stocco, M. R., \& Holahan, M. R. (2015). Attenuation of MK-801-induced behavioral perseveration by typical and atypical antipsychotic pretreatment in rats. Behavioral Neuroscience, 129(4), 399-411.

Tzakis, N., Bosnic, T., Ritchie, T., Dixon, K., \& Holahan, M. R. (2016). The effect of AMPA receptor blockade on spatial information acquisition, consolidation and expression in juvenile rats. Neurobiology of Learning and Memory, 133, 145-156.

Vetter-O'Hagen, C. S., \& Spear, L. P. (2012). Hormonal and physical markers of puberty and their relationship to adolescent-typical novelty-directed behavior. Developmental Psychobiology, 54(5), 523-535.

van Duijvenvoorde, A. C. K., Peters, S., Braams, B. R., \& Crone, E. A. (2016). What motivates adolescents? Neural responses to rewards and their influence on adolescents' risk taking, learning, and cognitive control. Neuroscience and Biobehavioral Reviews, 70, 135-147.

van Kuyck, K., Gabriëls, L., Cosyns, P., Arckens, L., Sturm, V., Rasmussen, S., \& Nuttin, B. (2007). Behavioural and physiological effects of electrical stimulation in the nucleus accumbens: a review. Acta Neurochirurgica. Supplement, 97(Pt 2), 375-391.

Voorn, P., Kalsbeek, A., Jorritsma-Byham, B., \& Groenewegen, H. J. (1988). The pre- and postnatal development of the dopaminergic cell groups in the ventral mesencephalon and the dopaminergic innervation of the striatum of the rat. Neuroscience, 25(3), 857-887.

Wade, T. R., de Wit, H., \& Richards, J. B. (2000). Effects of dopaminergic drugs on delayed reward as a measure of impulsive behavior in rats. Psychopharmacology, 150(1), 90-101.

Waelti, P., Dickinson, A., \& Schultz, W. (2001). Dopamine responses comply with basic assumptions of formal learning theory. Nature, 412(6842), 43-48.

Wakabayashi, K. T., Fields, H. L., \& Nicola, S. M. (2004). Dissociation of the role of nucleus accumbens dopamine in responding to reward-predictive cues and waiting for reward. Behavioural Brain Research, 154(1), 19-30. 
Wang, L., \& Pitts, D. K. (1994). Postnatal development of mesoaccumbens dopamine neurons in the rat: electrophysiological studies. Brain Research. Developmental Brain Research, 79(1), 19-28.

Wang, J., Zhao, Z., Liang, Q., Wang, X., Chang, C., Wang, J., \& Gao, G. (2008). The nucleus accumbens core has a more important role in resisting reactivation of extinguished conditioned place preference in morphine-addicted rats. The Journal of International Medical Research, 36(4), 673-681.

Wang, H.-X., \& Gao, W.-J. (2009). Cell type-specific development of NMDA receptors in the interneurons of rat prefrontal cortex. Neuropsychopharmacology: Official Publication of the American College of Neuropsychopharmacology, 34(8), 2028-2040.

Watson, J. B. (1913). Psychology as the behaviorist views it. Psychological Review. Wegener, N., Nagel, J., Gross, R., Chambon, C., Greco, S., Pietraszek, M., Danysz, W. (2011). Evaluation of brain pharmacokinetics of $(+)$ MK-801 in relation to behaviour. Neuroscience Letters, 503(1), 68-72.

Williams, D. J., Crossman, A. R., \& Slater, P. (1977). The efferent projections of the nucleus accumbens in the rat. Brain Research, 130(2), 217-227.

Wise, R. A., \& Schwartz, H. V. (1981). Pimozide attenuates acquisition of lever-pressing for food in rats. Pharmacology, Biochemistry, and Behavior, 15(4), 655-656.

Wirtshafter, D. (2000). A comparison of the patterns of striatal Fos-like immunoreactivity induced by various dopamine agonists in rats. Neuroscience Letters, 289(2), 99-102.

Wong, E. H., Kemp, J. A., Priestley, T., Knight, A. R., Woodruff, G. N., \& Iversen, L. L. (1986). The anticonvulsant MK-801 is a potent N-methyl-D-aspartate antagonist. Proceedings of the National Academy of Sciences of the United States of America, 83(18), 7104-7108.

Wozniak, K. M., Pert, A., \& Linnoila, M. (1990). Antagonism of 5-HT3 receptors attenuates the effects of ethanol on extracellular dopamine. European Journal of Pharmacology, 187(2), 287-289.

Wyvell, C. L., \& Berridge, K. C. (2000). Intra-accumbens amphetamine increases the conditioned incentive salience of sucrose reward: enhancement of reward "wanting" without enhanced "liking" or response reinforcement. The Journal of Neuroscience: The Official Journal of the Society for Neuroscience, 20(21), 8122-8130.

Yager, L. M., Garcia, A. F., Wunsch, A. M., \& Ferguson, S. M. (2015). The ins and outs of the striatum: role in drug addiction. Neuroscience, 301, 529-541.

Yamaguchi, T., Sheen, W., \& Morales, M. (2007). Glutamatergic neurons are present in the rat 
ventral tegmental area: Glutamatergic neurons in the VTA. The European Journal of Neuroscience, 25(1), 106-118.

Yamaguchi, T., Wang, H.-L., Li, X., Ng, T. H., \& Morales, M. (2011). Mesocorticolimbic glutamatergic pathway. The Journal of Neuroscience: The Official Journal of the Society for Neuroscience, 31(23), 8476-8490.

Yashiro, K., \& Philpot, B. D. (2008). Regulation of NMDA receptor subunit expression and its implications for LTD, LTP, and metaplasticity. Neuropharmacology, 55(7), 1081-1094.

Yokel, R. A., \& Wise, R. A. (1976). Attenuation of intravenous amphetamine reinforcement by central dopamine blockade in rats. Psychopharmacology, 48(3), 311-318.

Yonghui, L., Xigeng, Z., Yunjing, B., Xiaoyan, Y., \& Nan, S. (2006). Opposite effects of MK-801 on the expression of food and morphine-induced conditioned place preference in rats. Journal of Psychopharmacology , 20(1), 40-46.

Zaborszky L., Alheid G. F., Beinfeld M. C., Eiden L. E., Heimer L. and Palkovits M. (1985) Cholecystokinin innervation of the ventral striatum: a morphological and radioimmunological study. Neuroscience 14, 427453.

Zaczek, R., Hedreen, J. C., \& Coyle, J. T. (1979). Evidence for a hippocampal-septal glutamatergic pathway in the rat. Experimental Neurology, 65(1), 145-156.

Zahm, D. S., \& Brog, J. S. (1992). On the significance of subterritories in the "accumbens" part of the rat ventral striatum. Neuroscience, 50(4), 751-767.

Zahm, D. S., \& Heimer, L. (1993). Specificity in the efferent projections of the nucleus accumbens in the rat: comparison of the rostral pole projection patterns with those of the core and shell. The Journal of Comparative Neurology, 327(2), 220-232.

Zamanillo, D., Sprengel, R., Hvalby, O., Jensen, V., Burnashev, N., Rozov, A., Sakmann, B. (1999). Importance of AMPA receptors for hippocampal synaptic plasticity but not for spatial learning. Science, 284(5421), 1805-1811.

Zavitsanou, K., Lim, C. K., Purves-Tyson, T., Karl, T., Kassiou, M., Banister, S. D., Weickert, C. S. (2014). Effect of maternal immune activation on the kynurenine pathway in preadolescent rat offspring and on MK801-induced hyperlocomotion in adulthood: amelioration by COX-2 inhibition. Brain, Behavior, and Immunity, 41, 173-181.

Zorumski, C. F., \& Izumi, Y. (2012). NMDA receptors and metaplasticity: mechanisms and possible roles in neuropsychiatric disorders. Neuroscience and Biobehavioral Reviews, 36(3), 989-1000. 
